\title{
Rebate Strategy Selection and Channel Coordination of Competing Two-Echelon Supply Chains
}

\author{
Ziling Wang, ${ }^{1}$ Rong Zhang, ${ }^{2}$ and Bin Liu $\mathbb{D}^{1}$ \\ ${ }^{1}$ School of Economics and Management, Shanghai Maritime University, Pudong 201306, Shanghai, China \\ ${ }^{2}$ Research Center of Logistics, Shanghai Maritime University, Pudong 201306, Shanghai, China \\ Correspondence should be addressed to Bin Liu; liubin@shmtu.edu.cn
}

Received 16 September 2020; Revised 24 January 2021; Accepted 6 March 2021; Published 22 March 2021

Academic Editor: Xueyong Liu

Copyright (c) 2021 Ziling Wang et al. This is an open access article distributed under the Creative Commons Attribution License, which permits unrestricted use, distribution, and reproduction in any medium, provided the original work is properly cited.

Rebate has long been a crucial tool that has attracted researchers from a diverse range of fields including marketing and supply chain management. When a manufacturer uses a retailer for reaching end customers, the rebate strategy undertakes an additional dimension. Here we show whether the two rebate strategies, manufacturer rebate and channel rebate, can be the optimal choice for the manufacturer and the retailer. And we aim at full coordination with rebate. Game theory is exploited to identify the equilibrium rebate decisions, which are fully characterized with two rebate strategies considering rebate sensitivity. Furthermore, we demonstrate how the decisions depend on parameters, such as market size, rebate redemption rate, and competition intensity in monopoly and duopoly supply chain systems. Our work also coordinates the supply chain with two coordination policies and examines if they can achieve full coordination. Counterintuitive findings suggest that the channel rebate with sensitivity and discrimination is not effective and the manufacturer rebate is the unique optimal option. Besides, the coordination can be realized with a centralized rebate in monopoly setting when the manufacturer forgoes her own interest. Then full coordination can be achieved in duopoly setting with a new coordination policy, rebate combination, given the redemption rate for the channel rebate is lower compared with the manufacturer rebate. Managerial insights are suggested that offering rebates with discrimination can have significant inventory and coordination policy implications and can lead to a double win under a well-controlled redemption rate.

\section{Introduction}

Rebate, admittedly, is a modern and salient type of sale promotion in the marketing mix toward consumers' daily lives. According to an industrial survey, about $50 \%$ of supply chain members utilize rebates as part of their customer loyalty and promotional mix [1]. A study of UK shopper behavior reveals that one in three customers prefer rebates on consumer packaged goods and three in four customers are inclined to instant rebates on appliances and electronics [2]. Firms regard rebate as a useful tool or strategy [3-7]. Rebates will not lower the customers' future price expectations, especially in consumer electronics, automotive, and food product industries for a few purposes. In some cases, rebates are commonly applied to increase sales, expand demands, decrease inventories, and coordinate supply chains $[8,9]$.
Different implementations exist for all kinds of rebates in monopoly and duopoly supply chain systems. As an illustration, a manufacturer provides a rebate of US $\$ 100$ to end customers for every Nikon Digital camera sold for US\$600. Channel rebates are epidemic in the network hardware switching industry [10] and pervasive in the software industry, for instance, Lotus and Symantec [11, 12]. Unilever and $P \& G$, two major manufacturers of the fast-moving consumer goods industry, generally tender manufacturer rebates to consumers. Furthermore, Canon and Epson, two oligarch competitors of the electronics industry, distribute substitutable products through retailers, such as Staples. Both also offer manufacturer rebates for a valid purchase. Retailers can benefit from a high demand due to manufacturers' rebate programs. Thus, retailers are in an incentive to subsidize manufacturers. Many retailers, such as Walmart 
and Staples, invest resources to promote these programs in their stores and on their websites. Some retailers support manufacturer rebate programs in the form of sharing the fixed cost [13]. A properly designed channel rebate can achieve channel coordination [14]. Channel rebates can also coordinate supply chains under special arrangements, for example, long-term relationship contract, where the wholesale price and retail price, respectively, can be modified by the manufacturer and the retailer [15].

However, these existing theories only investigate redemption with customers' sensitivity to the manufacturer rebate and do not involve channel rebates. In effect, channel rebate's realizing coordination is based upon the condition that customers are homogeneous and retailers cannot engage in discrimination. Although few customers redeem rebates for a particularly low redemption rate [16-23], redemption with regard to rebate sensitivity is noteworthy either [24]. Therefore, we fill this gap by expressly addressing the following research questions:

(1) What is the incentive for manufacturers to furnish the manufacturer rebate when they sell to a common retailer?

(2) How does customers' sensitivity to the channel rebate with or without discrimination affect supply chain members' profits?

(3) Does centralized profit or coordination exist under such an assigned rebate strategy? If not, is there any other rebate strategy that can bring about coordination or full coordination?

We present two supply chain systems: a monopoly supply chain system of one manufacturer selling to one retailer and a duopoly one with two competing manufacturers selling substitutable products through a common retailer to customers. Note that these customers are heterogeneous in their rebate sensitivity. We also focus on the two most popular rebate strategies, manufacturer rebate and channel rebate. The former is the payment from the manufacturer to the end customers upon the purchase of the manufacturer's product. The manufacturer can take full advantage of the "slippage effect" to implement rebate discrimination with less than $100 \%$ redemption rate. The latter is a rebate the manufacturer passes to the retailer on the basis of the quantity ordered. In turn, the retailer may pass a fraction of the rebate to the end customers. Moreover, we implement customers' sensitivity to realistic channel rebates and outline whether the strategy is effective with or without discrimination.

In this paper, we shall first identify customers' redemption rates related to sensitivity for both two rebate strategies and competition intensity as the key performance drivers. We then characterize how they affect firm decisions and profits. Our analysis demonstrates collusion may occur among supply chain members with the manufacturer rebate in the two systems, and it is the unique optimal choice without coordination. The manufacturer rebate can also create a win-win situation where the retailer can obtain a free ride to gain the most profit, whereas in the channel rebate with customers' sensitivity and discrimination, the profit of the overall supply chain is no better than that of the norebate strategy. Next, a centralized rebate policy is implemented to examine whether the two supply chain systems can achieve coordination. Our results indicate that coordination can be realized in the monopoly system when the manufacturer is willing to forgo her own interest. Otherwise, the overall supply chain can be better off with a comparatively small market size. On the contrary, the coordination may fail in the duopoly setting. Thus, we put forward a new coordination policy of mixing the manufacturer rebate and the channel rebate with discrimination. The overall supply chain here can be fully coordinated with a rebate combination if the redemption rate for the channel rebate is lower than the manufacturer rebate.

Our work is related to the large volume of literature on rebates in the past several decades. Most studies in the field focus on the effectiveness and impact of rebates. Gerstner and Hess [8] examined the use of retailer and manufacturer rebates and revealed that offering rebates is profitable for manufacturers without price discrimination. Taylor [14] introduced a new form of channel rebates-target rebate, in which the rebate is paid for each unit sold beyond a specified target level, on the basis of the linear rebate paid just for each unit sold. Arcelus et al. [25] explored the joint influences of integrated pricing, rebate, and ordering decisions on the channel rebate and the manufacturer rebate within a stochastic price-dependent demand framework. Khouja [3] revealed that proposing rebates can have good pricing and inventory policy implications and lead to an increase in profit. Aydin and Porteus [26] indicated that manufacturer rebate can boost a retailer's margin but not the whole system, whereas channel rebate may simultaneously perform better. Demirag et al. [27] developed a game-theoretical model to investigate the impact of retailer incentives and customer rebate promotions on pricing and ordering policies. They implied that customer rebates can be more profitable than retailer incentives in some cases. Arcelus et al. [28] outlined the two rebate strategies of manufacturer rebate and retailer rebate may be equally advantageous.

In this stream, a considerable amount of studies have been conducted on a one-manufacturer-one-retailer relationship. Gerstner and Hess [29] examined four types of price promotions including trade deals only, manufacturer rebates only, their combination, and channel rebates with two consumer segments. They observed conditions under which a retailer motivates to effectively serve both segments. Chen et al. [16] used a case study comparing rebates with coupons and indicated that the rebate can play an efficient role in price discrimination among consumers. Lu and Moorthy [30] analyzed the difference between a rebate and coupon when uncertain redemption costs are resolved and identified. They revealed that rebates perform better in price discrimination. Cho et al. [31] studied the equilibrium of a vertical competition game between a manufacturer and a retailer and investigated the effect of competition on rebate decisions. Baysar et al. [32] conducted a Stackelberg game in a monopoly supply chain system. They argued that uncertain market conditions are more beneficial to manufacturer 
rebates. However, retailer incentive is always out a good figure with deterministic demand. Given structure power in the supply chain, Khouja and Jing [33] analyzed a Stackelberg game with a manufacturer offering rebates as a leader and a retailer acting as a follower.

Supply chain coordination, on which we exhaustively review the latest research here, is relevant to our work. Consulting cost-sharing, Liu et al. [34] discussed the efficacy of cost-sharing in advertising with a model of two competing manufacturer-retailer supply chains' selling partially substitutable products that may differ in market size. They suggested that firms performing advertising can rather bear the costs entirely. Pu et al. [35] suggested a cost-sharing contract to achieve more profitable outcomes. Chen et al. [36] revealed that profit-sharing can coordinate the dualchannel supply chain. Xu et al. [37] indicate a two-way revenue-sharing contract can coordinate the supply chain and achieves a double win. Heydari and Ghasemia [38] proposed a customized revenue-sharing strategy, which can also coordinate the two-echelon reverse supply chain. Li et al. [39] develop the impact of revenue-sharing and costsharing contracts presented by a retailer on emission reduction efforts and firms' profitability. Other coordination contrasts and their effectiveness comparison were also implied, like buyback, risk-sharing, and return policy [40-43]. Modak et al. [44] explored channel coordination and profit division issues of a manufacturer-distributor-duopolistic retailers supply chain. They found the manufacturer prefers collusion, Stackelberg, and Cournot, while the retailer prefers the reverse and both prefer backward sequential bargaining.

Rebate contracts, the focus of this study, however, have gained relatively little attention. Taylor [14] first demonstrated that a designed target rebate can achieve coordination and a win-win outcome when demand is not influenced by sales effort. Taylor and Xiao [45] characterized the optimal rebate and return contracts. They claimed that a retailer and manufacturer, including the total system, may benefit from rebate contracts instead of return contrasts. Chiu et al. [46] developed two target sales rebates (TSR): (1) an innovative menu of TSR contracts with fixed order quantity and (2) a sophisticated case. The differences between them are analytically examined, thereby generating meaningful managerial insights.

Our research is closely related to research by $\mathrm{Ha}$ et al. [13], Wang et al. [47], and Muzaffar et al. [15]. Ha et al. [13] pioneered a multistage game, including two manufacturers selling substitutable products through a common retailer with less than $100 \%$ redemption rate called the slippage effect. Wang et al. [47] further investigated the impacts of leadership strategy on profits and study rebate decisions under different strategies. However, they both only considered the manufacturer rebate. The new contribution of this paper to the literature is that it considers the slippage effect of customers' sensitivity involved in both systems of the manufacture rebate and channel rebate with and without discrimination. Muzaffar et al. [15] included manufacturer and channel rebates and showed that the latter can coordinate supply chains under special arrangements. On the contrary, a wholesale price discount does not confer the supply chain coordination mechanism, and the retailer must pass a portion of the discount to the end customers. Accordingly, such coordination becomes collusion. However, their work only considered a one-to-one supply chain, where customers are homogeneous in sensitivity for the channel rebate, and the manufacturer and retailer cannot engage in discrimination on them, to wit, $100 \%$ redemption rate. Our contribution to the literature is that we develop a duopoly supply chain with two competing manufacturers, on the basis of the one-to-one system, selling substitutable products through a common retailer to customers, where these customers are heterogeneous in their rebate sensitivity. We show that the channel rebate cannot realize coordination with respect to rebate discrimination on heterogeneous customers. Additionally, we propose a new coordination policy of mixing the manufacturer rebate and the channel rebate, where the retailer exerts discrimination on consumers in the channel rebate, and full coordination can be achieved.

\section{Materials and Methods}

2.1. Model Setting. We first set out to determine a monopoly supply chain system involving one manufacturer (she) selling a single product through a common retailer (he) to consumers who are heterogeneous in their rebate sensitivity. The manufacturer is viewed as the Stackelberg leader, whereas the retailer is the follower. We investigate the manufacturer and channel rebates in the two-echelon supply chains, where the manufacturer can select either type of the rebate strategy denoted as $T=\{M, C\}$, that is to say, two rebate settings, a manufacturer rebate only (denoted as the superscript $\mathrm{M}$ ) and a channel rebate only (denoted as the superscript $\mathrm{C}$ ). We assume that the manufacturer should decide whether to provide a rebate before other decisions because launching a rebate is time-consuming.

The supply chain system can be described as a multistage game with the following sequence of events:

(1) The manufacturer must decide either to offer the rebate, denoted by $\mathrm{R}$, or not to do it, denoted by $\mathrm{N}$, with a related fixed cost. Consequently, we denote the manufacturer's rebate decisions as $Z^{s}=\{R, N\}$.

(2) After observing the rebate decision, the manufacturer selects the type of rebate strategy $T$. The manufacturer has three combinations, $Z^{\mathrm{s}} \mathrm{T}=$ $\{R M, R C, N N\}$, where $Z^{s} T=N N$ is designated as the benchmark.

(3) Then, the manufacturer determines her wholesale price $\omega^{\mathrm{Z}^{\mathrm{s}} \mathrm{T}}$ and rebate value $r^{\mathrm{RM}}$ if she selects the manufacturer rebate.

(4) Given the manufacturer's rebate strategies and price decisions, the retailer determines his retail price $p^{Z^{s} T}$ and rebate value $r^{\mathrm{RC}}$ if the manufacturer chooses the channel rebate.

(5) The manufacturer produces to meet her demands, and the firms acquire their payoffs. 
We next develop the monopoly supply chain system to a duopoly system, including two manufacturers (indexed by $\mathrm{X}$ or $\mathrm{Y}$ ) selling substitutable products through a common retailer to consumers who are heterogeneous in their rebate sensitivity. The system also conforms to the manufacturer Stackelberg process. The multistage game in the duopoly system is the same as the monopoly one. Each manufacturer $\mathrm{i}(\mathrm{i}=\mathrm{X}, \mathrm{Y})$ determines her wholesale price $\omega_{\mathrm{i}}^{\mathrm{Z}^{\mathrm{d}} \mathrm{T}}$ and rebate value $r_{\mathrm{i}}{ }^{\mathrm{Z}} \mathrm{M}$, if any. By contrast, the retailer determines his retail prices $p_{\mathrm{i}}^{\mathrm{Z}^{\mathrm{d}} \mathrm{T}}$ and rebate value $r_{\mathrm{i}} \mathrm{Z}^{\mathrm{d}} \mathrm{C}$, if any. In addition, we assume that the two manufacturers move simultaneously to make price decisions in the duopoly system, where we only consider the symmetric setting. That is, both manufacturers either offer rebates or not. Therefore, the manufacturer's rebate decisions are denoted as $\mathrm{Z}^{\mathrm{d}}=\mathrm{Z}_{X}^{d}$ $Z_{Y}^{d}=\{R R, N N\}$. The first and second letters denote manufacturer $\mathrm{X}$ and manufacturer Y's rebate decisions, respectively, where $Z_{X}^{d}=\{R, N\}$ and $Z_{Y}^{d}=\{R, N\}$. Consequently, the manufacturer has three combinations, $\mathrm{Z}^{\mathrm{d}} \mathrm{T}=$ $\{R R M, R R C, N N N\}$. The multistage game in the duopoly setting is similar to the monopoly setting.
2.2. Demand Function. Research by Cai [48] suggested that rebates help discriminate consumers who are heterogeneous in their price sensitivity as not every consumer redeems rebates. We divide consumers into two segments, where they are heterogeneously rebate-sensitive and rebate-insensitive, respectively. Research by Lu and Moorthy [30] argued that consumers with different incomes may have different opportunity costs of time, so they can incur different redemption costs. As a result, we assume rebate-sensitive consumers incur a low redemption cost $C_{\mathrm{L}}$. On the contrary, rebate-insensitive consumers incur a high redemption cost $C_{\mathrm{H}}$ for the complexity of the redemption steps or their high cost of time, where $0 \leq C_{\mathrm{L}}<C_{\mathrm{H}}$. We derive the demand functions in the duopoly supply chain system by following a similar approach from research by $\mathrm{Ha}$ et al. [13] and Wang et al. [47]. The approach was also developed from research by Zhang et al. [49] and Chung [50]. The utility function of a representative consumer is given by

$$
\begin{aligned}
& \left(q_{X}^{Z^{d} T}+q_{Y}^{Z^{d} T}\right) a-(1 / 2)\left[\left(q_{X}^{Z^{d} T}\right)^{2}+\left(q_{Y}^{Z^{d} T}\right)^{2}+2 \gamma q_{X}^{Z^{d} T} q_{Y}^{Z^{d} T}\right] \\
& \quad-\left\{p_{X}^{Z^{d} T}-\max \left[\theta r_{X}^{Z^{d} C},\left(r_{X}^{Z^{d} C}-C_{C}\right)\right]-\max \left[m r_{X}^{Z^{d} M},\left(r_{X}^{Z^{d} M}-C_{M}\right)\right]\right\} q_{X}^{Z^{d} T} \\
& \quad-\left\{p_{Y}^{Z^{d} T}-\max \left[\theta r_{Y}^{Z^{d} C},\left(r_{Y}^{Z^{d} C}-C_{C}\right)\right]-\max \left[m r_{Y}^{Z^{d} M},\left(r_{Y}^{Z^{d} M}-C_{M}\right)\right]\right\} q_{Y}^{Z^{d} T}
\end{aligned}
$$

where $a$ is the market size; $q_{\mathrm{i}}^{\mathrm{Z}^{\mathrm{d}} \mathrm{T}}, p_{\mathrm{i}}^{\mathrm{Z}^{\mathrm{d}} \mathrm{T}}$, and $r_{\mathrm{i}}^{\mathrm{Z}^{\mathrm{d}} \mathrm{T}}$ are the consumption quantity, retail price, and rebate value of product i produced by manufacturer i, respectively; and $C_{\mathrm{C}}$ and $C_{\mathrm{M}}$ are consumers' estimated redemption costs of manufacturer and channel rebates. Here, $\gamma \in[0,1)$, which is generally interpreted as the competition intensity among manufacturers, capturing the substitutability of the two products. We suppose that the customers are homogeneous in their redemption costs of rebates proposed by two competing manufacturers.

Moreover, research by Chen et al. [51] pointed out through some studies that consumers insidiously display overconfidence in the personal forecast. Such an optimism bias is called "slippage effect," which can let customers overestimate their likelihood of redeeming a rebate offer and commit a blunder in estimating the effort involved in the redemption. Research by Tasoff and Letzler [52] indicated that the expected redemption rates exceed the actual redemption rates by $49 \%$ because of stamp and envelope costs, cost of time, and loss of form, all of which explain a high redemption cost. Therefore, to contemplate the "slippage effect" in differentiating heterogeneous consumers in terms of their rebate sensitivity, we follow the methods of research by Wang et al. [47] and view $m \in(0,1]$ as the redemption rate for the manufacturer rebate and $\theta \in(0,1]$ as the one for the channel rebate in the utility function. Namely, if $C_{\mathrm{M}}=C_{\mathrm{C}}=C_{\mathrm{L}}=0$, then consumers are rebate-sensitive and can incur a $100 \%$ redemption rate $(m=\theta=1)$. If $C_{\mathrm{M}}=C_{\mathrm{C}}=C_{\mathrm{H}}$, then the redemption costs are high such that the consumers are rebate-insensitive and can incur redemption rates less than $100 \%(m \in(0,1), \theta \in(0,1))$, instead of being prohibited from redeeming rebates. For tractability, the proportion of rebate-sensitive consumers is made identical to rebate-insensitive consumers in the market (otherwise, too many parameters can be stacked in the formulas).

Hence, the utility function of a representative rebatesensitive consumer is given by

$$
\begin{gathered}
\left(q_{\mathrm{X}}^{\mathrm{Z}^{\mathrm{d}} \mathrm{T}}+q_{\mathrm{Y}}^{\mathrm{Z}^{\mathrm{d}} \mathrm{T}}\right) a-(1 / 2)\left[\left(q_{\mathrm{X}}^{\mathrm{Z}^{\mathrm{d}} \mathrm{T}}\right)^{2}+\left(q_{\mathrm{Y}}^{\mathrm{Z}^{\mathrm{d}} \mathrm{T}}\right)^{2}+2 \gamma q_{\mathrm{X}}^{\mathrm{Z}^{\mathrm{d}} \mathrm{T}} q_{\mathrm{Y}}^{\mathrm{Z}^{\mathrm{d}} \mathrm{T}}\right] \\
-\left(p_{\mathrm{X}}^{\mathrm{Z}^{\mathrm{d}} \mathrm{T}}-r_{\mathrm{X}}^{\mathrm{Z}^{\mathrm{d}} \mathrm{C}}-r_{\mathrm{X}}^{\mathrm{Z}^{\mathrm{d}} \mathrm{M}}\right) q_{\mathrm{X}}^{\mathrm{Z}^{\mathrm{d}} \mathrm{T}}-\left(p_{\mathrm{Y}}^{\mathrm{Z}^{\mathrm{d}} \mathrm{T}}-r_{\mathrm{Y}}^{\mathrm{Z}^{\mathrm{d}} \mathrm{C}}-r_{\mathrm{Y}}^{\mathrm{Z}^{\mathrm{d}} \mathrm{M}}\right) q_{\mathrm{Y}}^{\mathrm{Z}^{\mathrm{d}} \mathrm{T}} .
\end{gathered}
$$


Given $p_{\mathrm{i}}^{\mathrm{Z}^{\mathrm{d}} \mathrm{T}}$ and $r_{\mathrm{i}}^{\mathrm{Z}^{\mathrm{d}} \mathrm{T}}$, the optimal consumption quantities $t_{\mathrm{i}}^{\mathrm{Z}^{\mathrm{d}} \mathrm{T}}$ for rebate-sensitive consumers are stated by the following demand functions:

$$
\begin{aligned}
& t_{\mathrm{X}}^{\mathrm{Z}^{\mathrm{d}} \mathrm{T}}=\frac{(1-\gamma) a-\left(p_{\mathrm{X}}^{\mathrm{Z}^{\mathrm{T}} \mathrm{T}}-r_{\mathrm{X}}^{\mathrm{Z}^{\mathrm{d}} \mathrm{C}}-r_{\mathrm{X}}^{\mathrm{Z}^{\mathrm{d}} \mathrm{M}}\right)+\gamma\left(p_{\mathrm{Y}}^{\mathrm{Z}^{\mathrm{d}}}-r_{\mathrm{Y}}^{\mathrm{Z}^{\mathrm{d}} \mathrm{C}}-r_{\mathrm{Y}}^{\mathrm{Z}^{\mathrm{d}} \mathrm{M}}\right)}{1-\gamma^{2}}, \\
& t_{\mathrm{Y}}^{\mathrm{Z}^{\mathrm{d}} \mathrm{T}}=\frac{(1-\gamma) a-\left(p_{\mathrm{Y}}^{\mathrm{Z}^{\mathrm{d}} \mathrm{T}}-r_{\mathrm{Y}}^{\mathrm{Z}^{\mathrm{d}} \mathrm{C}}-r_{\mathrm{Y}}^{\mathrm{Z}^{\mathrm{d}} \mathrm{M}}\right)+\gamma\left(p_{\mathrm{X}}^{\mathrm{Z}^{\mathrm{d}} \mathrm{T}}-r_{\mathrm{X}}^{\mathrm{Z}^{\mathrm{d} C}}-r_{\mathrm{X}}^{\mathrm{Z}^{\mathrm{d}} \mathrm{M}}\right)}{1-\gamma^{2}} .
\end{aligned}
$$

The utility function of a representative rebate-insensitive consumer is as follows:

$$
\begin{aligned}
& \left(q_{\mathrm{X}}^{\mathrm{Z}^{\mathrm{d}} \mathrm{T}}+q_{\mathrm{Y}}^{\mathrm{Z}^{\mathrm{d}} \mathrm{T}}\right) a-(1 / 2)\left[\left(q_{\mathrm{X}}^{\mathrm{Z}^{\mathrm{d}} \mathrm{T}}\right)^{2}+\left(q_{\mathrm{Y}}^{\mathrm{Z}^{\mathrm{d}} \mathrm{T}}\right)^{2}+2 \gamma q_{\mathrm{X}}^{\mathrm{Z}^{\mathrm{d}} \mathrm{T}} q_{\mathrm{Y}}^{\mathrm{Z}^{\mathrm{d}} \mathrm{T}}\right] \\
& -\left(p_{\mathrm{X}}^{\mathrm{Z}^{\mathrm{d}} \mathrm{T}}-\theta r_{\mathrm{X}}^{Z^{\mathrm{d}} \mathrm{C}}-m r_{\mathrm{X}}^{Z^{\mathrm{d}} \mathrm{M}}\right) q_{\mathrm{X}}^{\mathrm{Z}^{\mathrm{d}} \mathrm{T}}-\left(p_{\mathrm{Y}}^{\mathrm{Z}^{\mathrm{d}} \mathrm{T}}-\theta r_{\mathrm{Y}}^{\mathrm{Z}^{\mathrm{d}} \mathrm{C}}-m r_{\mathrm{Y}}^{\mathrm{Z}^{\mathrm{d}} \mathrm{M}}\right) q_{\mathrm{Y}}^{\mathrm{Z}^{\mathrm{d}} \mathrm{T}} .
\end{aligned}
$$

Given $p_{\mathrm{i}}^{\mathrm{d}^{\mathrm{d}} \mathrm{T}}$, the optimal consumption quantities $k_{\mathrm{i}}^{\mathrm{Z}^{\mathrm{d}} \mathrm{T}}$ for rebate-insensitive consumers are stated by the following demand functions:

$$
\begin{aligned}
& k_{\mathrm{X}}^{\mathrm{Z}^{\mathrm{d}} \mathrm{T}}=\frac{(1-\gamma) a-\left(p_{\mathrm{X}}^{\mathrm{Z}^{\mathrm{d}} \mathrm{T}}-\theta r_{\mathrm{X}}^{\mathrm{Z}^{\mathrm{d}} \mathrm{C}}-m r_{\mathrm{X}}^{\mathrm{Z}^{\mathrm{d}} \mathrm{M}}\right)+\gamma\left(p_{\mathrm{Y}}^{\mathrm{Z}^{\mathrm{d}} \mathrm{T}}-\theta r_{\mathrm{Y}}^{\mathrm{Z}^{\mathrm{d}} \mathrm{C}}-m r_{\mathrm{Y}}^{\mathrm{Z}^{\mathrm{d}} \mathrm{M}}\right)}{1-\gamma^{2}}, \\
& k_{\mathrm{Y}}^{\mathrm{Z}^{\mathrm{d}} \mathrm{T}}=\frac{(1-\gamma) a-\left(p_{\mathrm{Y}}^{\mathrm{Z}^{\mathrm{d}} \mathrm{T}}-\theta r_{\mathrm{Y}}^{\mathrm{Z}^{\mathrm{d}} \mathrm{C}}-m r_{\mathrm{Y}}^{Z^{\mathrm{d}} \mathrm{M}}\right)+\gamma\left(p_{\mathrm{X}}^{\mathrm{Z}^{\mathrm{d}} \mathrm{T}}-r \theta_{\mathrm{X}}^{\mathrm{Z}^{\mathrm{d}} \mathrm{C}}-m r_{\mathrm{X}}^{\mathrm{Z}^{\mathrm{d}} \mathrm{M}}\right)}{1-\gamma^{2}} .
\end{aligned}
$$

Let $D_{i}^{\mathrm{Z}^{\mathrm{d} T}}=(1 / 2)\left(t_{i}^{Z^{\mathrm{d}} \mathrm{T}}+k_{i}^{Z^{\mathrm{d}} \mathrm{T}}\right)$ as the total demand of the product $i$. The relevant demand functions displayed in Appendix A in the monopoly supply chain system can be inferred from the duopoly system. No data are used to support this study.

\section{Results and Discussion}

3.1. Monopoly Supply Chain System. In light of the rebate decision $\mathrm{Z}^{\mathrm{s}}$ and rebate strategy $\mathrm{T}$ from the manufacturer, we solve for the equilibrium retail price, wholesale price, and rebate value, if any, by optimizing the profit functions of the retailer and manufacturer. We also obtain firm profits. The fixed cost of the rebate is not involved in the manufacturer's profit functions because it is a sunk cost and does not have any impact on the manufacturer's decisions, and rebate discrimination is wielded in the manufacturer rebate. All the equilibrium results are summarized in Table 1 , and all proofs are provided in Appendix B.
3.1.1. Benchmark. If the manufacturer does not launch any rebate program, given ${ }_{\omega N}^{\mathrm{NN}}$, the retailer maximizes his profit $\pi_{\mathrm{R}}^{\mathrm{NN}}=\left(p^{\mathrm{NN}}-\omega^{\mathrm{NN}}\right) D^{\mathrm{NN}}$. Then the manufacturer maximizes her profit $\pi_{\mathrm{M}}^{\mathrm{NN}}=\omega^{\mathrm{NN}} D^{\mathrm{NN}}$, and the optimal wholesale price, retail price, and profits can be obtained.

3.1.2. Manufacturer Rebate. If the manufacturer presents the manufacturer rebate, given $\omega^{\mathrm{RM}}$ and $r^{\mathrm{RM}}$, the retailer maximizes his profit $\pi_{\mathrm{R}}^{\mathrm{RM}}=\left(p^{\mathrm{RM}}-\omega^{\mathrm{RM}}\right) D^{\mathrm{RM}}$. Then, the manufacturer maximizes her profit $\pi_{\mathrm{M}}^{\mathrm{RM}}=(1 / 2)$ $\left(\omega^{\mathrm{RM}}-m r^{\mathrm{RM}}\right) t^{\mathrm{RM}}+(1 / 2) \omega^{\mathrm{RM}} k^{\mathrm{RM}}$, and the other optimal prices and profits involved can be derived.

Lemma 1. For the manufacturer rebate in the monopoly supply chain, we have the following:

(i) $\omega^{\mathrm{RM}^{*}}, \quad r^{\mathrm{RM}^{*}}, \quad p^{\mathrm{RM}^{*}}, \quad \pi_{\mathrm{R}}^{\mathrm{RM}^{*}}$, and $\pi_{\mathrm{M}}^{\mathrm{RM}^{*}}$ initially decrease and then increase in $m$ 
TABLE 1: Equilibrium results in the monopoly supply chain system.

\begin{tabular}{|c|c|c|}
\hline \multicolumn{2}{|c|}{ Benchmark } & Manufacturer rebate \\
\hline$\omega^{*}$ & $(a / 2)$ & $\left(a m(5-4 m) / 8 m-8 m^{2}-1\right)$ \\
\hline$r^{*}$ & - & $\left(2 a / 8 m-8 m^{2}-1\right)$ \\
\hline$p^{*}$ & $(3 a / 4)$ & $\left(a m(7-6 m) / 8 m-8 m^{2}-1\right)$ \\
\hline$\pi_{\mathrm{R}}^{*}$ & $\left(a^{2} / 16\right)$ & $\left(4 a^{2}(1-m)^{2} m^{2} /\left(8 m-8 m^{2}-1\right)^{2}\right)$ \\
\hline$\pi_{M}^{*}$ & $\left(a^{2} / 8\right)$ & $\left(a^{2}(1-m) m / 8 m-8 m^{2}-1\right)$ \\
\hline
\end{tabular}

(ii) A threshold exists in $m$ for the manufacturer and retailer

Lemma 1 elucidates that, at a relatively low redemption level, the higher the redemption level, the lower the wholesale price and profits for the manufacturer. Videlicet, the manufacturer can only lower the wholesale price to stimulate rebate sensitivity for improving the redemption level at a low redemption rate. However, as the wholesale price is lowered to a certain point, the redemption rate can reach a relevant threshold. In addition, the higher the redemption rate, the higher the wholesale price and profits for the manufacturer. At a comparatively high redemption level, the market demand is close to saturation, and the low wholesale price set cannot boost the demand anymore. Therefore, as the redemption rate becomes comparatively high, the manufacturer can fix a high wholesale price to earn additional profits. The impacts of the redemption rate on retailers are similar.

Rebate value may always be expected to decrease in the redemption rate due to the assumption that a manufacturer raises the rebate value to enhance the redemption level. Thus, when redemption becomes high, the manufacturer can reduce the rebate value. Nevertheless, the retail price is related to the wholesale price and rebate value. If the negative influence of the redemption rate is greater than its positive influence, the retailer may be worse off. Here, we acknowledge that retailers must set a high retail price to gain profit when the redemption rate reaches a relatively high level.

3.1.3. Channel Rebate. If the manufacturer furnishes the channel rebate, given $\omega^{\mathrm{RC}}$ and $r^{\mathrm{RC}}$, the retailer maximizes his profit $\pi_{\mathrm{R}}^{\mathrm{RC}}=(1 / 2)\left(p^{\mathrm{RC}}-\omega^{\mathrm{RC}}\right) t^{\mathrm{RC}}+(1 / 2)\left[p^{\mathrm{RC}}-\omega^{\mathrm{RC}}+(1-\right.$ $\left.\theta) r^{\mathrm{RC}}\right] k^{\mathrm{RC}}$ by not exerting rebate discrimination on customers. Then the manufacturer must maximize her profit $\pi_{\mathrm{M}}^{\mathrm{RC}}=\left(\omega^{\mathrm{RC}}-r^{\mathrm{RC}}\right) D^{\mathrm{RC}}$, and we can only obtain an optimal relationship between the wholesale price and rebate value, $\omega^{\mathrm{RC}}=r^{\mathrm{RC}^{*}}+(a / 2)$. The same equilibrium results as the benchmark are then derived.

If employing rebate discrimination on customers, the retailer maximizes his profit $\pi_{\mathrm{R}}^{\mathrm{RC}}=(1 / 2)\left[p^{\mathrm{RC}}-\omega^{\mathrm{RC}}+(1-\right.$ $\left.\theta) r^{\mathrm{RC}}\right] t^{\mathrm{RC}}+(1 / 2)\left(p^{\mathrm{RC}}-\omega^{\mathrm{RC}}+r^{\mathrm{RC}}\right) k^{\mathrm{RC}}$. Then the optimal wholesale price and rebate value for the manufacturer become negative.

Lemma 2. The channel rebate is ineffective whether the retailer implements rebate discrimination on customers or not.

The effects of the channel rebate on the manufacturer and retailer are counterintuitive. For the retailer not to exert rebate discrimination on customers, the manufacturer only decides her price margin. That is, no matter how many rebate values the retailer sets; she can make an increment of $(a / 2)$. The retail margin aggrandized by the rebate might not offset the increase in the wholesale price. Consequently, the retailer selects the no-rebate strategy, resulting in the manufacturer's profit identical to the benchmark. Conversely, if the retailer exerts rebate discrimination, the manufacturer may be reluctant in offering a channel rebate. Therefore, whether the retailer implements rebate discrimination, a conflict exists between the manufacturer and retailer under the channel rebate. The following proposition presents the optimal choice of rebate strategy in the monopoly supply chain system.

Proposition 1. For $\mathrm{Z}^{\mathrm{S}} \mathrm{T}=\{\mathrm{RM}, \mathrm{RC}, \mathrm{NN}\}:$ (a) $\pi_{\mathrm{M}}^{\mathrm{RC}^{*}}=$ $\pi_{\mathrm{M}}^{\mathrm{NN}^{*}}<\pi_{\mathrm{M}}^{\mathrm{RM}^{*}}$. (b) $\pi_{\mathrm{R}}^{\mathrm{RC}^{*}}=\pi_{\mathrm{R}}^{\mathrm{NN}^{*}}<\pi_{\mathrm{R}}^{\mathrm{RM}^{*}}$.

Proposition 1 confirms collusion among supply chain members with the manufacturer rebate in the monopoly system. Collusion can create a win-win situation. The increasing rebate value can reduce the double marginalization caused by the high wholesale price, and the retailer can obtain a free ride to gain the most profit, as depicted in Figure 1. In the long run, the channel rebate has the same impact as the no-rebate policy. Customers' sensitivity to the channel rebate affects supply members more than the manufacturer rebate, regardless of the discrimination. Accordingly, in the monopoly supply chain system without coordination, the manufacturer rebate is the unique optimal choice.

3.2. Duopoly Supply Chain System. Considering the rebate decision $Z^{\mathrm{d}}$ and rebate strategy $\mathrm{T}$ from competing manufacturers, we figure out the equilibrium retail prices, wholesale prices, and rebate values, if any, by optimizing the profit functions of the manufacturers and retailer, and we also obtain firm profits. Similarly, the fixed costs do not have any impact on manufacturers' decisions, and rebate discrimination is involved in the manufacturer rebate. All the equilibrium results are summarized in Table 2 .

3.2.1. Benchmark. If the two competing manufacturers do not undertake any rebate program, given $\omega_{i}^{\mathrm{NNN}}$, the retailer maximizes his profit $\pi_{\mathrm{R}}^{\mathrm{NNN}}=\left(p_{\mathrm{X}}^{\mathrm{NNN}}-\omega_{\mathrm{X}}^{\mathrm{NNN}}\right) D_{\mathrm{X}}^{\mathrm{NNN}}+$ $\left(p_{\mathrm{Y}}^{\mathrm{NNN}}-\omega_{\mathrm{Y}}^{\mathrm{NNN}}\right) D_{\mathrm{Y}}^{\mathrm{NNN}}$. Then the manufacturers should maximize their profits $\pi_{\mathrm{i}}^{\mathrm{NNN}}=\omega_{\mathrm{i}}^{\mathrm{NNN}} D_{\mathrm{i}}^{\mathrm{NNN}}$, and the optimal wholesale prices, retail prices, and profits can be obtained.

3.2.2. Manufacturer Rebate. If the manufacturers provide the manufacturer rebate, given $\omega_{i}^{\mathrm{RRM}}$ and $r_{i}^{\mathrm{RRM}}$, the retailer 


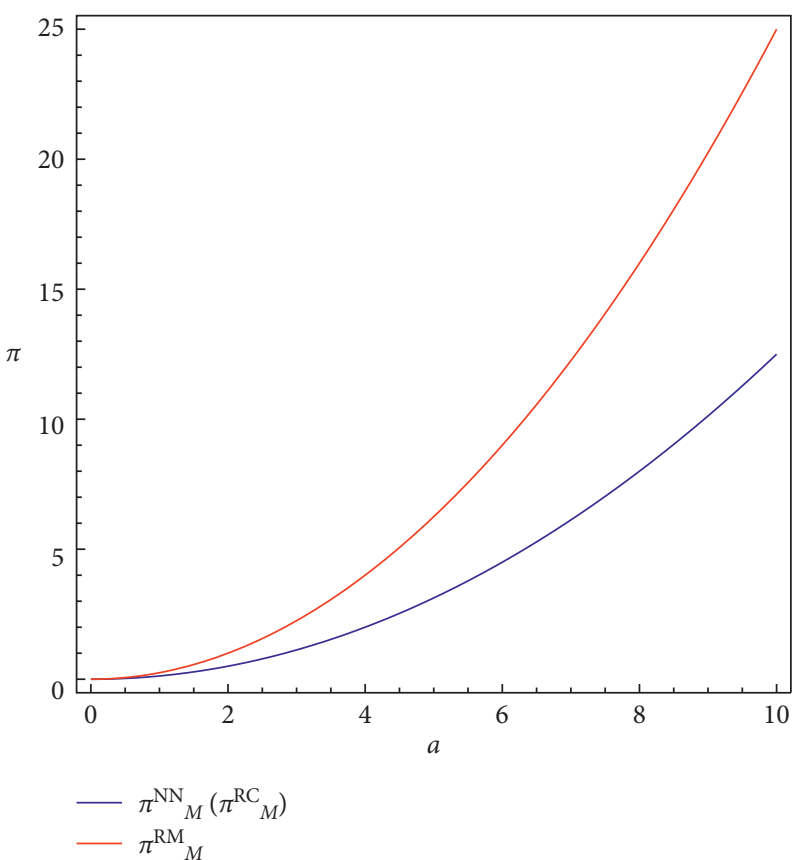

(a)

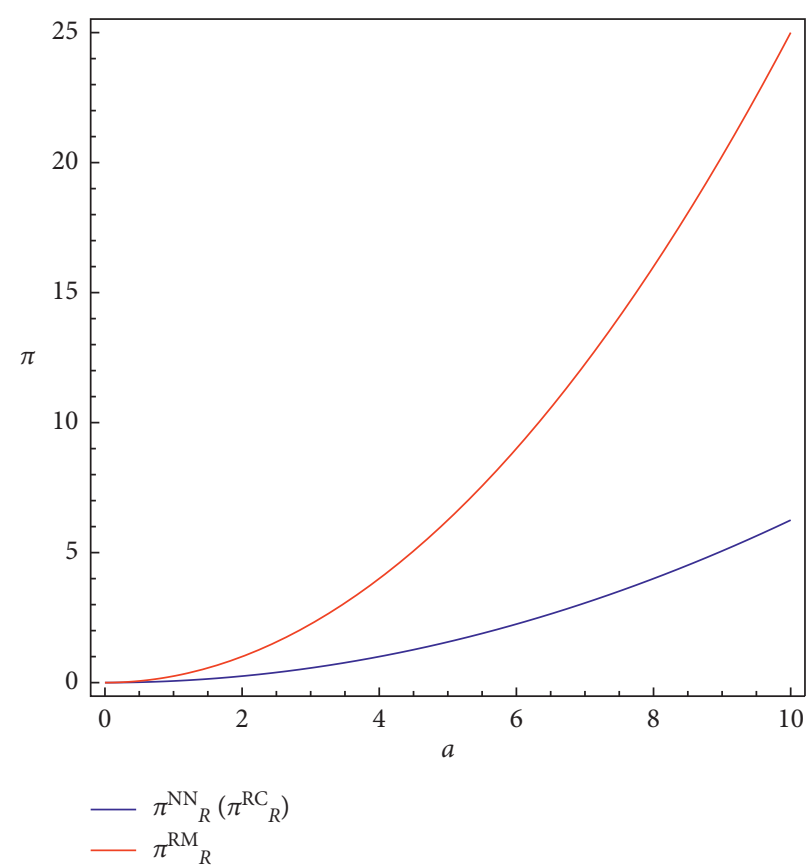

(b)

FIGURE 1: Manufacturer's and retailer's profits in the monopoly supply chain system versus $a(m=1 / 2)$. (a) Manufacturer's profits. (b) Retailer's profits.

TABLE 2: Equilibrium results in the duopoly supply chain system.

\begin{tabular}{lcc}
\hline & Benchmark & Manufacturer rebate \\
\hline$\omega_{\mathrm{i}}^{*}$ & $(a(1-\gamma) / 2-\gamma)$ & $\left(a m(5+2 m(-2+\gamma)-2 \gamma)(-1+\gamma) / 1-2 m(-2+\gamma)^{2}+2 m^{2}(-2+\gamma)^{2}-\gamma\right)$ \\
$r_{\mathrm{i}}^{*}$ & - & $\left(2 a(-1+\gamma) / 1-2 m(-2+\gamma)^{2}+2 m^{2}(-2+\gamma)^{2}-\gamma\right)$ \\
$p_{\mathrm{i}}^{*}$ & $(a(3-2 \gamma) / 2(2-\gamma))$ & $\left(a m\left[-7+8 \gamma-2 \gamma^{2}+m\left(6-7 \gamma+2 \gamma^{2}\right)\right] / 1-2 m(-2+\gamma)^{2}+2 m^{2}(-2+\gamma)^{2}-\gamma\right)$ \\
$\pi_{\mathrm{R}}^{*}$ & $\left(a^{2} / 2(2-\gamma)^{2}(1+\gamma)\right)$ & $\left(2 a^{2}(1-m)^{2} m^{2}(2-\gamma)^{2} /(1+\gamma)\left[-1+2 m(-2+\gamma)^{2}-2 m^{2}(-2+\gamma)^{2}+\gamma\right]^{2}\right)$ \\
$\pi_{\mathrm{i}}^{*}$ & $\left(a^{2}(1-\gamma) / 2(2-\gamma)^{2}(1+\gamma)\right)$ & $\left(a^{2}(1-m) m(-1+\gamma) /\left[1-2 m(-2+\gamma)^{2}+2 m^{2}(-2+\gamma)^{2}-\gamma\right](1+\gamma)\right)$ \\
\hline
\end{tabular}

maximizes his profit $\pi_{\mathrm{R}}^{\mathrm{RRM}}=\left(p_{\mathrm{X}}^{\mathrm{RRM}}-\omega_{\mathrm{X}}^{\mathrm{RRM}}\right) D_{\mathrm{X}}^{\mathrm{RRM}}+$ $\left(p_{\mathrm{Y}}^{\mathrm{RRM}}-\omega_{\mathrm{Y}}^{\mathrm{RRM}}\right) D_{\mathrm{Y}}^{\mathrm{RRM}}$. Then, the manufacturers maximize their profits $\pi_{\mathrm{i}}^{\mathrm{RRM}}=(1 / 2)\left(\omega_{\mathrm{i}}^{\mathrm{RRM}}-m r_{\mathrm{i}}^{\mathrm{RRM}}\right) t_{\mathrm{i}}^{\mathrm{RRM}}+(1 / 2)$ $\omega_{i}^{\mathrm{RRM}} k_{\mathrm{i}}^{\mathrm{RRM}}$, and the other associated optimal decisions are derived.

Lemma 3. For the manufacturer rebate in the duopoly supply chain, we have the following:

(i) $\omega_{\mathrm{i}}^{\mathrm{RRM}^{*}}$ initially decreases and then increases in $m$ if $\gamma<\gamma_{1}$

(ii) $\omega_{\mathrm{i}}^{\mathrm{RRM}^{*}}$ constantly increases in $m$ for $\gamma \geq \gamma_{1}$

(iii) $p_{\mathrm{i}}^{\mathrm{RRM}^{*}}$ initially decreases and then increases in $m$ if $\gamma<\gamma_{2}$

(iv) $p_{\mathrm{i}}^{\mathrm{RRM}^{*}}$ perpetually increases in $m$ for $\gamma \geq \gamma_{2}$, where $\gamma_{1} \leq \gamma_{2}$

Lemma 3 shows that, compared with the monopoly supply chain system, the redemption rate has different influences on the wholesale price with comparable substitutability in the duopoly system. When the competition between two manufacturers is less intense (i.e., $\gamma<\gamma_{1}$ ), the impact of the redemption level on the wholesale price is similar to the monopoly setting. When the competition is intense (i.e., $\gamma \geq \gamma_{1}$ ), the wholesale price always increases in the redemption rate. That is to say, when both manufacturers offer rebates in a competitive market, they are confronted with a low wholesale price. Therefore, they can no longer reduce the price to raise the redemption level. A threshold also exists in product substitutability, allowing the redemption rate to make a difference to the retailer price.

Lemma 4. For the manufacturer rebate in the duopoly supply chain system, $r_{\mathrm{i}}^{\mathrm{RRM}^{*}}, \pi_{\mathrm{i}}^{\mathrm{RRM}^{*}}$, and $\pi_{\mathrm{R}}^{\mathrm{RRM}^{*}}$ decrease and then increase in $m$ with any $\gamma$.

Lemma 4 indicates that the impact of customers' redemption rate on rebate values and supply chain members' profits is not subject to competition level between the two manufacturers. The effect is concordant with the result of the manufacturer rebate in the monopoly supply chain system. In addition, a threshold exists in the redemption rate for the members' profits.

The interaction between the redemption rate and substitutability reflects that the instinct in manufacturer 
competition is price competition and the coaction between manufacturers is greater than that between retailers. Based on our analysis, both manufacturers can only lessen rebate values, not wholesale prices with exceedingly competitive substitutability. Doing so raises the redemption rate at a low redemption level for capturing a potential demand.

3.2.3. Channel Rebate. If the manufacturers tender the channel rebate, the retailer maximizes his profit $\pi_{\mathrm{R}}^{\mathrm{RRC}}=(1 / 2) \sum_{\mathrm{i}=\mathrm{X}, \mathrm{Y}}\left\{\left(p_{\mathrm{i}}^{\mathrm{RRC}}-\omega_{\mathrm{i}}^{\mathrm{RRC}}\right) t_{\mathrm{i}}^{\mathrm{RRC}}+\left[p_{\mathrm{i}}^{\mathrm{RRC}}-\omega_{\mathrm{i}}^{\mathrm{RRC}}+(1\right.\right.$ $\left.\left.-\theta) r_{\mathrm{i}}^{\mathrm{RRC}}\right] k_{\mathrm{i}}^{\mathrm{RRC}}\right\}$ by not exerting rebate discrimination on customers. Then, the manufacturers maximize their profits $\pi_{\mathrm{i}}^{\mathrm{RRC}}=\left(\omega_{\mathrm{i}}^{\mathrm{RRC}}-r_{\mathrm{i}}^{\mathrm{RRC}}\right) D_{\mathrm{i}}^{\mathrm{RRC}}$. Similarly, we can only obtain the optimal relationship between wholesale prices and rebate values for the manufacturers, $\omega_{\mathrm{i}}^{\mathrm{RRC}}=r_{\mathrm{i}}^{\mathrm{RRC} C^{*}}+(a(1-\gamma)$ / $(2-\gamma))$. And the equilibrium results are also identical to the benchmark. If wielding rebate discrimination on customers, the retailer maximizes his profit $\pi_{\mathrm{R}}^{\mathrm{RRC}}=(1 / 2) \sum_{\mathrm{i}=\mathrm{X}, \mathrm{Y}}$ $\left\{\left[p_{\mathrm{i}}^{\mathrm{RRC}}-\omega_{\mathrm{i}}^{\mathrm{RRC}}+(1-\theta) r_{\mathrm{i}}^{\mathrm{RRC}}\right] t_{\mathrm{i}}^{\mathrm{RRC}}+\left(p_{\mathrm{i}}^{\mathrm{RRC}}-\omega_{\mathrm{i}}^{\mathrm{RRC}}+r_{\mathrm{i}}^{\mathrm{RRC}}\right)\right.$ $\left.k_{\mathrm{i}}^{\mathrm{RRC}}\right\}$. Then, the manufacturers can maximize their profits. The optimal wholesale prices and rebate values are also negative.

The effectiveness of the channel rebate in the duopoly supply chain system is similar to the monopoly setting. With the increment of the wholesale prices fixed by the manufacturers, the retailer not exerting rebate discrimination on customers can decide the nonzero rebate values. However, the retailer is inflicted with a negative profit. Consequently, the retailer can also select the no-rebate strategy, compelling the manufacturers' profits no better than the benchmark. The following proposition illuminates the optimal choice of the rebate strategy in the duopoly supply chain system.

Proposition 2. For $Z^{d} T=\{R R M, R R C, N N N\}$, we have the following:

$$
\begin{aligned}
& \text { (i) } \pi_{\mathrm{i}}^{\mathrm{RRC}}=\pi_{\mathrm{i}}^{\mathrm{NNN}^{*}}<\pi_{\mathrm{i}}^{\mathrm{RRM}^{*}} \\
& \text { (ii) } \pi_{\mathrm{R}}^{\mathrm{RRC}}=\pi_{\mathrm{R}}^{\mathrm{NNN}^{*}}<\pi_{\mathrm{R}}^{\mathrm{RRM}^{*}}
\end{aligned}
$$

Proposition 2 implies that, similar to the monopoly supply chain system, the manufacturer rebate can result in a double win, as depicted in Figure 2, and tacit collusion is developed between the two manufacturers although they are in a competitive relationship. Furthermore, the retailer can likewise take a free ride with the manufacturer rebate instead of the channel rebate. Moreover, sensitivity to the channel rebate has a greater effect on the supply chain in contrast to the manufacturer rebate. Accordingly, in the duopoly supply chain system without coordination, indubitably, the manufacturer rebate is still the exclusive optimal choice.

\subsection{Coordination in the Rebate Strategy}

3.3.1. Centralized Rebate. This work has examined the rebate strategy in a decentralized supply chain. However, the supply chain coordination is a pursuit of the largest interest normally achievable through a centralized system. A centralized rebate represents a supply chain where only one decision is made. Moreover, all the members maximize the overall supply chain profits by offering the maximum rebate instead of their own profits. As the manufacturer rebate strategy is the exclusive optimal selection for both the monopoly and duopoly supply chain systems, we just coordinate the supply chain with the manufacturer rebate in this section. If the profit of the overall supply chain is improved with the centralized rebate, then we manifest this supply chain coordinated.

In the monopoly supply chain system, the total supply chain profit is $\pi^{\mathrm{sTSC}}=(1 / 2)\left(p^{\mathrm{RM}}-m r^{\mathrm{sTSC}}\right)\left(a-p^{\mathrm{RM}}+\right.$ $\left.r^{\mathrm{sTSC}}\right)+(1 / 2) p^{\mathrm{RM}}\left(a-p^{\mathrm{RM}}+m r^{\mathrm{sTSC}}\right)$. We can obtain the optimal rebate value $\mathrm{r}^{s T S C *}=\left(2 a\left(-2+m^{2}\right) / 1-8 m+8 m^{2}\right)$ and derive the corresponding profits with coordination.

The retailer must sometimes forgo his own profits to make up to the optimal rebate value because the manufacturer cannot readily take on all the rebates under optimality. Correspondingly, how much is the manufacturer willing to sacrifice? We then investigate the maximum bound for the manufacturer. By substituting $\omega^{\mathrm{RM}^{*}}$ into the manufacturer's profit $\pi_{\mathrm{M}}^{\mathrm{RM}}$, we can give the manufacturer's upper bound $r_{\mathrm{M}}^{\mathrm{sTSC}} \leq\left(a\left(-3+m^{2}\right)\right.$ / $1-8 m+8 m^{2}$ ) for the rebate.

Proposition 3. For creating a centralized rebate in the monopoly supply chain, we have the following:

(i) The manufacturer and the retailer or the manufacturer alone must raise rebate up to $r^{\text {sTSC* }}$

(ii) If the manufacturer offers the rebate of $r^{\text {sTSC* }}$, then she is no better than the no-coordination policy

(iii) If the manufacturer offers the maximum rebate $r_{M}^{s T S C *}=\left(a\left(-3+m^{2}\right) / 1-8 m+8 m^{2}\right)$, then the retailer cannot pocket all his profits

In Part (ii), a Pareto improvement exists, indicating that the overall supply chain profit is enhanced. The manufacturer is no better than the no-rebate policy. By contrast, the retailer has a free ride to gain additional profits. This condition is illustrated as $\pi_{\mathrm{R}}^{\mathrm{sTSC}}$ in Figure 3. In Part (iii), if the manufacturer does not present all the rebates for a centralized rebate, then the retailer must promote the rebate value to $r^{\text {sTSC }}{ }^{*}$ by forgoing his own profit margin as a consumer discount. Therefore, the overall supply chain is in a good position (Pareto optimal) when the market size is comparatively small (i.e., $a<\left(3+7 m+4 m^{2}\right.$ / $\left.2+8 m+2 m^{2}\right)$ ), as depicted in Figure 4 . The increase in a manufacturer's profit can countervail the decrease in a retailer's profit. The end of the curve up warp suggests that when customers' redemption rate becomes relatively high, the Pareto optimal zone enlarges by boosting the potential demand.

In the duopoly supply chain system likewise, we can obtain the optimal rebate $r_{\mathrm{i}}^{\mathrm{dTSC}}=\left(a\left(-8+9 \gamma+m \gamma-2 \gamma^{2}+\right.\right.$ $\left.\left.2 m^{2}\left(2-3 \gamma+\gamma^{2}\right)\right) / 2\left(1-2 m(-2+\gamma)^{2}+2 m^{2}(-2+\gamma)^{2}-\gamma\right)\right)$ by substituting $p_{\mathrm{i}}^{\mathrm{RRM}}{ }^{*}$ into the related total supply chain profit function. Then we can derive the corresponding profits with coordination. Besides, the manufacturers' upper bound for the rebate is $r_{\mathrm{M}}^{\mathrm{dTSC}^{*}} \leq\left(a\left(-3+m^{2}\right)(1-\gamma) / 1-2 m\right.$ $\left.(-2+\gamma)^{2}+2 m^{2}(-2+\gamma)^{2}-\gamma\right)$. 


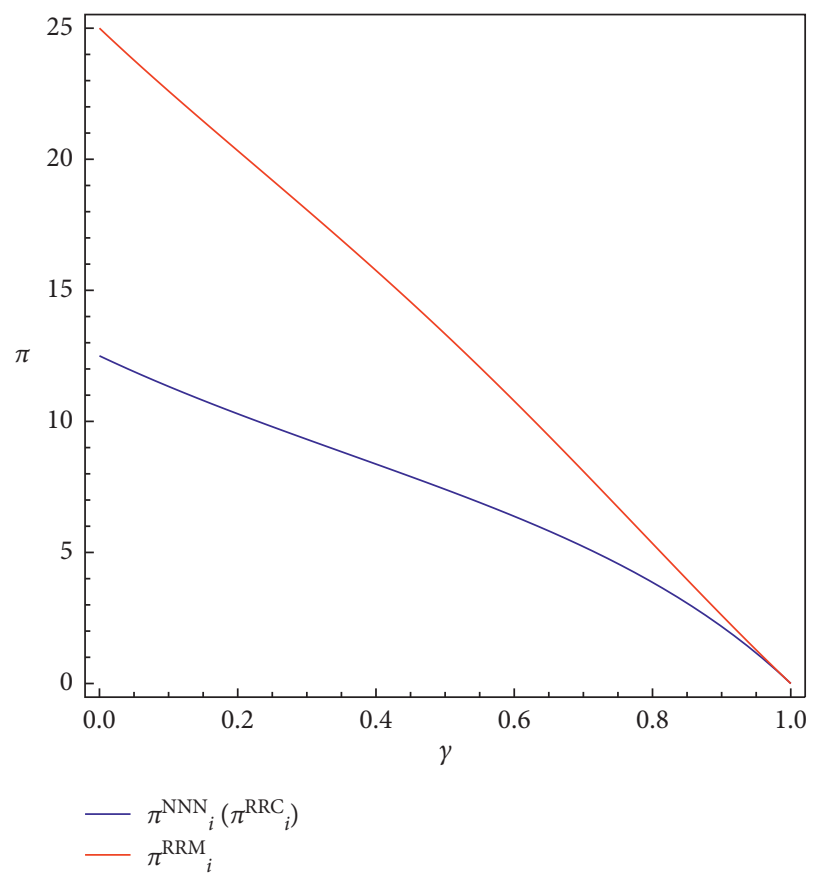

(a)

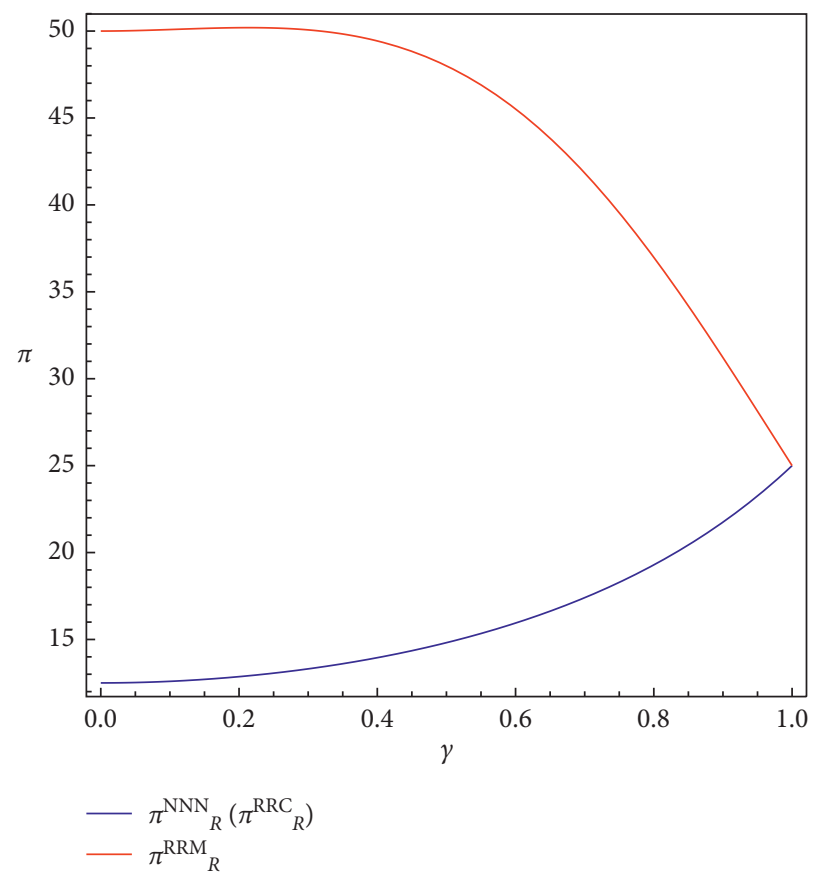

(b)

FiguRE 2: Manufacturers' and retailer's profits in the duopoly supply chain system versus $\gamma(a=10, m=(1 / 2))$. (a) Manufacturers' profits. (b) Retailer's profits.

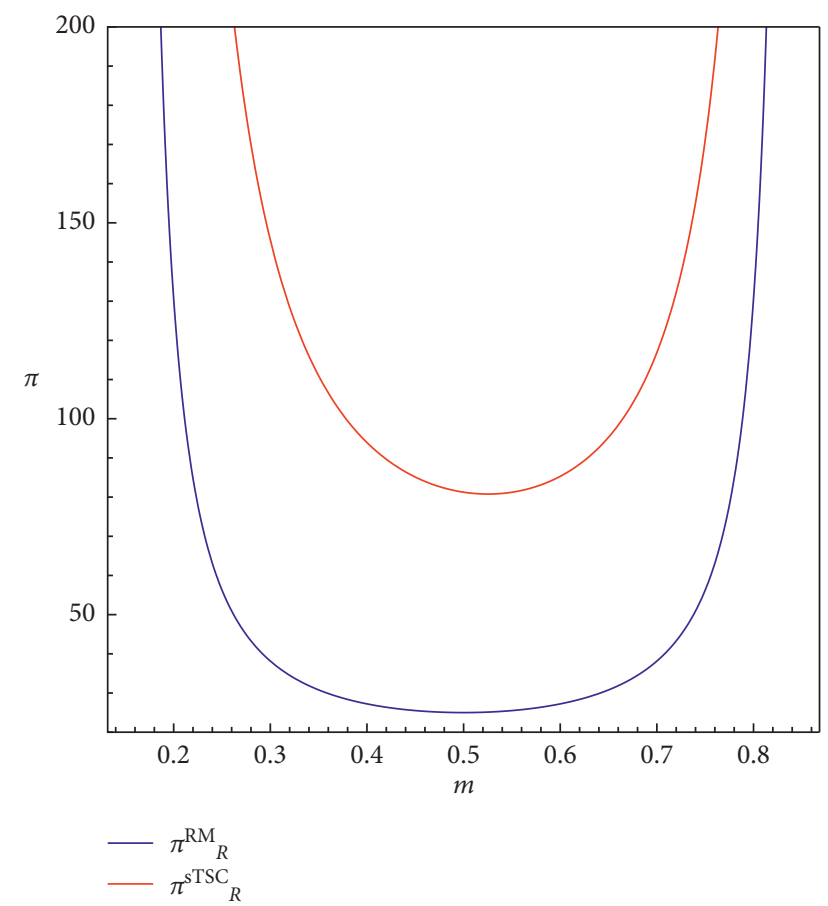

FIGURE 3: Comparison of the retailer's profit for the manufacturer and centralized rebates with manufacturer's offering $r^{\text {sTSC* }}$.

Proposition 4. For creating a centralized rebate in the duopoly supply chain system,

(i) The manufacturers and the retailer or the manufacturers alone must raise the rebate up to $r_{\mathrm{i}}^{\mathrm{dTSC}} \mathrm{C}^{*}$

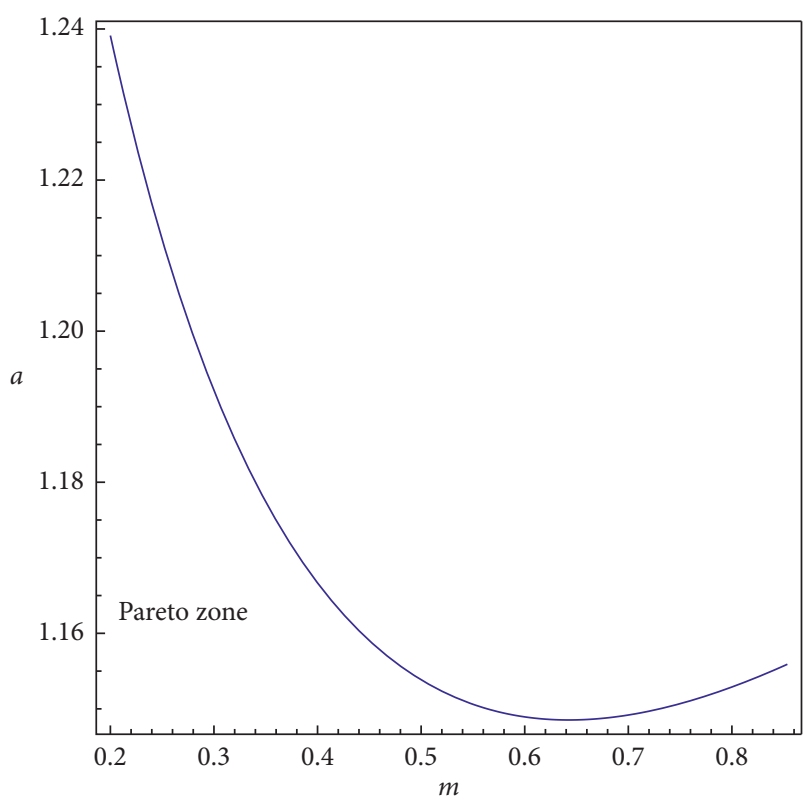

FIgURE 4: Pareto zone for full coordination under the centralized rebate with manufacturer's offering $r_{\mathrm{M}}^{\mathrm{sTSC} *}$.

(ii) If the manufacturers offer the rebate of $r_{i}^{\mathrm{dTSC}}{ }^{*}$, then they are worse off than the no-coordination policy

(iii) The manufacturers and the retailer fail to coordinate in the supply chain if the manufacturers merely offer the maximum rebate $r_{\mathrm{M}}^{\mathrm{dTSC}}=\left(a\left(-3+m^{2}\right)(1-\gamma)\right.$ / $\left.1-2 m(-2+\gamma)^{2}+2 m^{2}(-2+\gamma)^{2}-\gamma\right)$ 


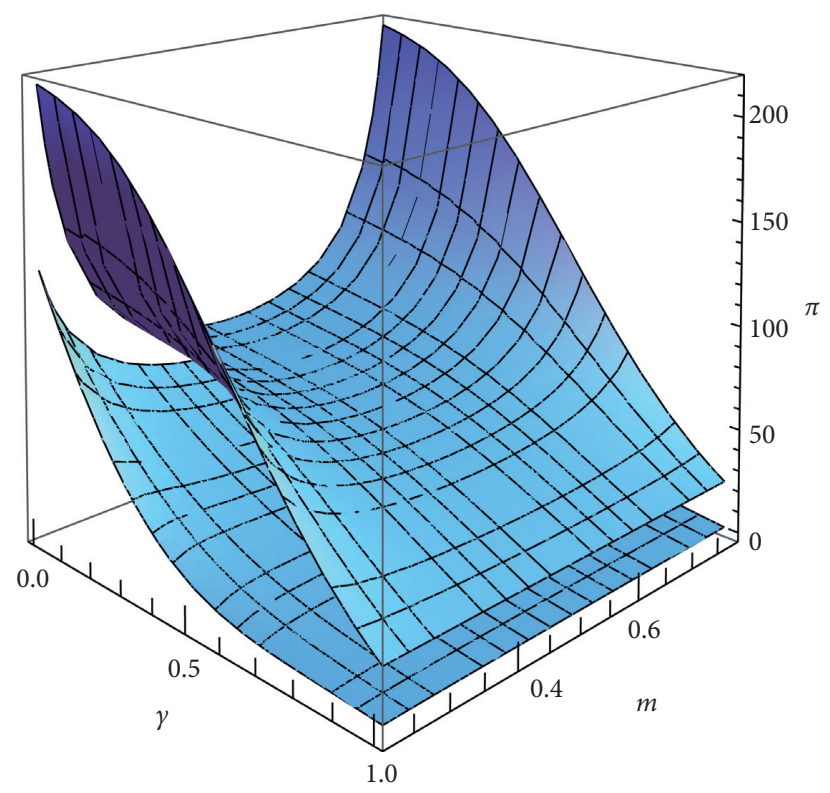

FIGURE 5: Changes in the overall supply chain profit under the centralized rebate with manufacturers' offering $r_{i}^{\mathrm{dTSC}}{ }^{*}$.

In Part (ii), the manufacturers might go downhill in the duopoly setting. Nevertheless, compared with the decentralized system, the overall supply chain is potentially ideal, as illustrated in Figure 5. The above and below curve surfaces represent the changes in the overall supply chain profit with redemption rate and substitutability. Such changes are attributed to the retailer's profit increment making up the manufacturers' wastage. To actualize the full coordination, the two competing manufacturers prefer to sacrifice themselves to expand the overall supply chain profit. In Part (iii), the overall supply chain profit could become aggravated compared with the monopoly system, even if the retailer would like to forgo his own interest to raise the rebate up to $r_{\mathrm{i}}^{\mathrm{dTSC} *}$. Note that the manufacturers' offering is only a part of the rebate values to customers. In other words, the centralized rebate policy in this condition may fail.

3.3.2. Rebate Combination. Based on our interpretation, the supply chain is unnecessarily better off in the centralized rebate if the manufacturer does not undertake all manufacturer rebates. Thus, we recommend rebate combination as a new coordination policy, where the manufacturers and retailer take rebate as a means to encourage demand. And the retailer implements discrimination on customers similar to manufacturers. On the one hand, the channel rebate is a practical and attractive price-controlling strategy. Specifically, it allows the manufacturers to control the retail price setting in the supply chain system, and the manufacturers might act as such to motivate the retailer to take further inventory. On the other hand, realizing the centralized rebate in real life is indeed tricky.

If the overall supply chain profit ameliorates compared with the no-rebate program, we treat the rebate combination as an effective coordination scheme. In addition, we assume that the customers may be simultaneously sensitive or insensitive to the rebates. All the equilibrium results are summarized in Table 3.

For the monopoly supply chain system, given $\omega^{\mathrm{BR}}, r^{\mathrm{BRM}}$, and $r^{\mathrm{BRC}}$, the retailer maximizes his profit $\pi_{\mathrm{R}}^{\mathrm{BR}}=(1 / 2)\left[p^{\mathrm{BR}}-\right.$ $\left.\omega^{\mathrm{BR}}+(1-\theta) r^{\mathrm{BRM}}\right] t^{\mathrm{BR}}+(1 / 2)\left(p^{\mathrm{BR}}-\omega^{\mathrm{BR}}+r^{\mathrm{BRM}}\right) k^{\mathrm{BR}}$, where $r^{\mathrm{BRM}}$ and ${ }_{r}^{\mathrm{BRC}}$ represent the rebate provided by the manufacturer and retailer, respectively. Then the manufacturer maximizes her profit $\pi_{\mathrm{M}}^{\mathrm{BR}}=(1 / 2)\left(\omega^{\mathrm{BR}}-m r^{\mathrm{BRM}}-r^{\mathrm{BRC}}\right) t^{\mathrm{BR}}+$ $(1 / 2)\left(\omega^{\mathrm{BR}}-r^{\mathrm{BRC}}\right) k^{\mathrm{BR}}$, and we can obtain the other optimal decisions.

For the duopoly supply chain system, given $\omega_{\mathrm{i}}^{\mathrm{BRR}}, r_{\mathrm{i}}^{\mathrm{BRRM}}$, and $r_{i}^{\mathrm{BRRC}}$, the retailer maximizes his profit $\pi_{\mathrm{R}}^{\mathrm{BRR}}=(1 / 2) \sum_{\mathrm{i}=\mathrm{X}, \mathrm{Y}}\left\{\left[p_{\mathrm{i}}^{\mathrm{BRR}}-\omega_{\mathrm{i}}^{\mathrm{BRR}}+(1-\theta) r_{\mathrm{i}}^{\mathrm{BRR}}\right] t_{\mathrm{i}}^{\mathrm{BRR}}+\left(p_{\mathrm{i}}^{\mathrm{BRR}}\right.\right.$ $\left.\left.-\omega_{\mathrm{i}}^{\mathrm{BRR}}+r_{\mathrm{i}}^{\mathrm{BRR}}\right) k_{\mathrm{i}}^{\mathrm{BRR}}\right\}$, where $r_{\mathrm{i}}^{\mathrm{BRRM}}$ and $r_{\mathrm{i}}^{\mathrm{BRRC}}$ represent the rebate offered by the manufacturers and retailer, respectively. Then the manufacturers maximize their profits $\pi_{\mathrm{i}}^{\mathrm{BRR}}=(1 / 2)\left(\omega_{\mathrm{i}}^{\mathrm{BRR}}-m r_{\mathrm{i}}^{\mathrm{BRRM}}-r_{\mathrm{i}}^{\mathrm{BRRC}}\right) t_{\mathrm{i}}^{\mathrm{BRR}}+(1 / 2)\left(\omega_{\mathrm{i}}^{\mathrm{BRR}}-\right.$ $\left.r_{\mathrm{i}}^{\mathrm{BRRC}}\right) k_{\mathrm{i}}^{\mathrm{BRR}}$, and we can obtain other related optimal results.

Proposition 5. For the rebate combination in the monopoly and duopoly supply chain systems, the Pareto optimal zone for the overall supply chain exists to achieve full coordination with $\theta<m$.

Proposition 5 indicates that, in both supply chain systems, the manufacturers and the retailer are better off with any $0 \leq \gamma<1$, if the redemption rate for the channel rebate is lower than the manufacturer rebate. To wit, the redemption rate for the channel rebate has a greater impact than the manufacturer rebate on the overall supply chain with the rebate combination. When $\theta \leq 0.5$ and $\theta<m<1$, the Pareto optimal zone maximization comes into reality for the overall supply chain to achieve full coordination. When $\theta>0.5$ and $\theta<m<\underset{m}{\theta>0.5}$, redemption rate goes relatively high. Otherwise, the Pareto optimal zone could become narrow when the redemption rate for the manufacturer rebate increases, as outlined in Figure 6. 


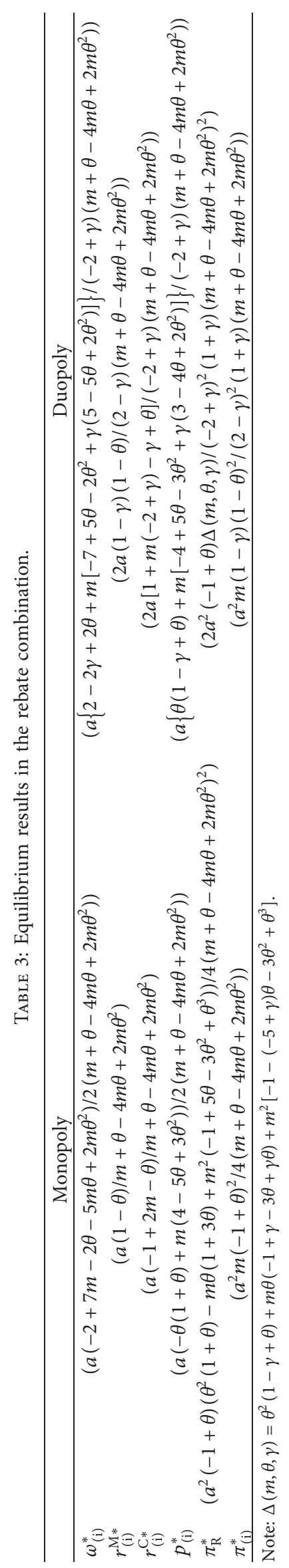




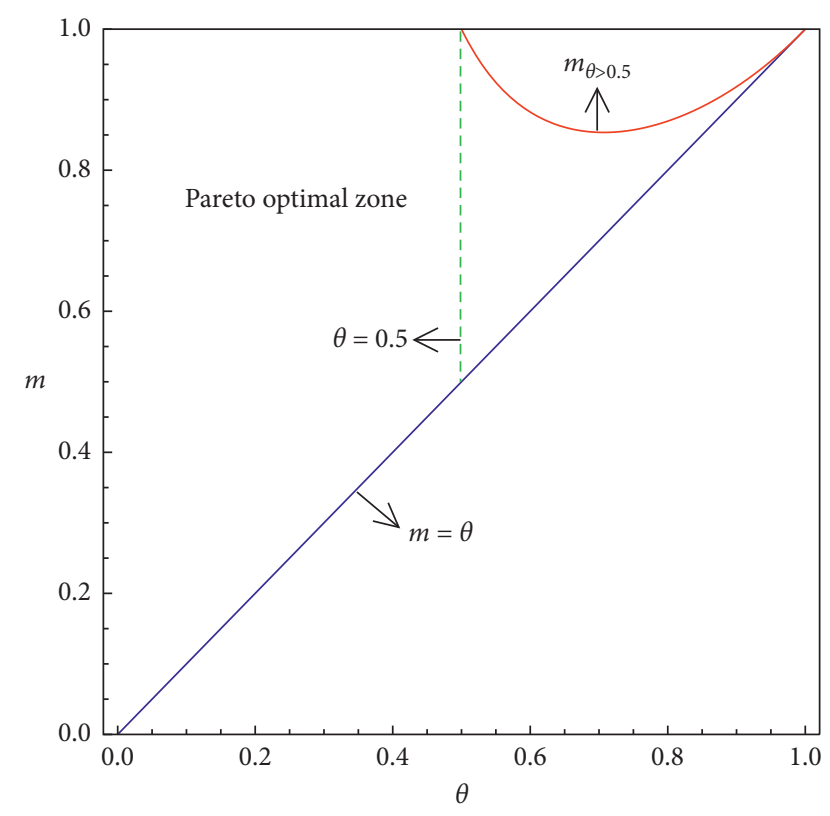

Figure 6: Pareto optimal zone under the rebate combination in both supply chain systems.

3.3.3. Managerial Insights. Our work offers crucial managerial insights for practitioners to further understand various rebate strategies in practice. For the monopoly and duopoly supply chain systems, if the manufacturers must deal with outdated stocks or style products to increase profits and embody the win-win situation, they should inspire the retailer to present channel rebates with noninstant redemption and redeeming efforts required so that the retailer can implement rebate discrimination on consumers. Moreover, for the sake of achieving the goal for double interests with rebate combination, the supply chain members should well control the redemption rate, and especially, the retailer has to dominate it for the channel rebate. Also, a retailer can purchase products from more than one manufacturer for additional profits, if appropriate competition exists under the rebate combination.

\section{Conclusion}

In this study, we examine the two most popular rebate strategies: (1) monopoly supply chain system with one manufacturer selling to one retailer and (2) duopoly supply chain system with two competing manufacturers selling to a common retailer. We also identify customers' redemption rates related to sensitivity for the manufacturer and channel rebates and competition intensity as the key performance drivers. What is more, we characterize how they affect firm decisions and profits. Then, we propose two coordination policies in the rebate strategy to meliorate the overall supply chain. Our analysis reveals novel and counterintuitive results. First, in the monopoly and duopoly supply chain systems, collusion may occur among supply chain members with the manufacturer rebate. This rebate is the unique optimal choice without coordination and can create a winwin situation where the retailer obtains a free ride to gain the most profit. In contrast, the overall supply chain is no better than the no-rebate policy under the channel rebate with customers' sensitivity, and competition intensity makes no difference to the manufacturers and the retailer. Second, with a centralized rebate on the manufacturer rebate strategy, coordination can be realized when the manufacturer is willing to forgo her own interest. Otherwise, the overall supply chain can be better off with a comparatively small market size in the monopoly system. By contrast, the coordination may fail in the duopoly setting. Accordingly, we develop a rebate combination as a new coordination policy with manufacturers and retailer offering rebates. Our analysis demonstrates that the overall supply chain can be fully coordinated with rebate combination if the redemption rate for the channel rebate is lower compared with the manufacturer rebate. Moreover, the Pareto optimal zone could be narrowed down with the increasing redemption level.

In addition, we have some implications for rebate programs in practice. If the manufacturer has many products in stock, then she must stimulate the retailer to participate in the channel rebate where the retailer can implement rebate discrimination on consumers. In addition, if the supply chain members prefer full coordination with proper competition intensity, the supply chain members should keep the redemption rate from increasing too much. Otherwise, the manufacturers and the retailer may be disadvantaged, thus ceasing rebate offers.

Our work has several limitations for application in reallife problems. For instance, we suppose that the redemption rate of the two rebate strategies is constant. However, it does not necessarily correspond with reality. It would be meaningful to extend our model to a more general situation, i.e., by considering that the redemption rate follows the uniform distribution. Besides, this study only views the manufacturer as the Stackelberg leader and does not consider the impact of power structure. With the development of retailing, retailers have a big say in the market. Thus, Nash bargaining may be an interesting topic to study in rebate decision. Finally, our work also does not account for the cost of rebating efforts, such as advertising, which is widely used in market expansion. Given that uncertainty still remains as to all the issues, we anticipate future research for resolution how the cost of rebate promotion affects the rebate strategy and who should bear the cost.

\section{Appendix}

\section{Demand functions of the monopoly system}

In the monopoly supply chain system, the utility function of a representative consumer is given by $q^{Z^{s} \mathrm{~T}} a-(1 / 2) q^{Z^{s} \mathrm{~T}}-$ $\left(p^{Z^{s} \mathrm{~T}}-\max \left[\theta r^{Z^{s} \mathrm{C}},\left(r^{Z^{s} \mathrm{C}}-C_{\mathrm{C}}\right)\right]-\max \left[m r^{\mathrm{Z}^{s} \mathrm{M}},\left(r^{\mathrm{Z}^{s} \mathrm{M}}-C_{\mathrm{M}}\right)\right]\right)$ $q^{\mathrm{Z}^{\mathrm{s}} \mathrm{T}}$, where $a$ is the market size and $q^{\mathrm{Z}^{\mathrm{s}} \mathrm{T}}, p^{\mathrm{Z}^{s} \mathrm{~T}}$, and $r^{\mathrm{Z}^{s} \mathrm{~T}}$ are the consumption quantity, retail price, and rebate value of product produced by the manufacturer, respectively.

The utility function of a representative rebate-sensitive consumer is given by $q^{Z^{s} \mathrm{~T}} a-(1 / 2) q^{Z^{s} \mathrm{~T}}-\left(p^{\mathrm{Z}^{\mathrm{S}} \mathrm{T}}-r^{Z^{s} \mathrm{C}}\right.$ $\left.-r^{Z^{s} \mathrm{M}}\right) q^{\mathrm{Z}^{\mathrm{S}} \mathrm{T}}$. Given $p^{\mathrm{Z}^{\mathrm{s}} \mathrm{T}}$ and $r^{\mathrm{Z}^{\mathrm{s}} \mathrm{T}}$, the optimal consumption 
quantities $t^{Z^{s} T *}$ for the rebate-sensitive consumers are given by the following demand functions: $t^{Z^{s} \mathrm{~T}}=a-p^{\mathrm{Z}^{s} \mathrm{~T}}+$ $r^{\mathrm{Z}^{\mathrm{s}} \mathrm{C}}+r^{\mathrm{Z}^{\mathrm{s}} \mathrm{M}}$.

The utility function of a representative rebate-insensitive consumer is given by $q^{Z^{s} \mathrm{~T}} a-(1 / 2) q^{\mathrm{Z}^{\mathrm{T}} \mathrm{T}}-\left(p^{\mathrm{Z}^{s} \mathrm{~T}}-\theta r^{\mathrm{Z}^{s} \mathrm{C}}-\right.$ $\left.m r^{Z^{s} \mathrm{M}}\right) q^{\mathrm{Z}^{\mathrm{s}} \mathrm{T}}$. Given $p^{\mathrm{Z}^{\mathrm{s}} \mathrm{T}}$, the optimal consumption quantities $k^{Z^{5} T *}$ for the rebate-insensitive consumers are given by the following demand functions: $k^{Z^{s} \mathrm{~T}}=a-p^{Z^{s} \mathrm{~T}}+\theta r^{Z^{s} \mathrm{C}}+$ $m r^{Z^{s} \mathrm{M}}$. Let $D^{\mathrm{Z}^{\mathrm{s}} \mathrm{T}}=(1 / 2)\left(t^{\mathrm{Z}^{\mathrm{s}} \mathrm{T}}+k^{\mathrm{Z}^{\mathrm{s}} \mathrm{T}}\right)$ as the total demand of the product.

\section{Proofs}

In the monopoly supply chain system, we have the following:

(1) For $\mathrm{Z}^{\mathrm{s}} \mathrm{T}=\mathrm{NN}$, the retailer and manufacturer maximize their profits with the negative Hessian matrices due to $\left(\partial^{2} \pi_{\mathrm{R}}^{\mathrm{NN}} / \partial p^{\mathrm{NN}^{2}}\right)=-2<0 \quad$ and $\left(\partial^{2} \pi_{\mathrm{M}}^{\mathrm{NN}} / \partial \omega^{\mathrm{NN}}\right)=-1<0$. Thus, the profits of the retailer and manufacturer satisfy the second-order condition for the maximum.

(2) For $Z^{s} \mathrm{~T}=\mathrm{RM}$, the retailer and manufacturer maximize their profits with the negative Hessian matrices due to $\left(\partial^{2} \pi_{\mathrm{R}}^{\mathrm{RM}} / \partial p^{\mathrm{RM}}{ }^{2}\right)=-2<0, \quad\left(\partial^{2} \pi_{\mathrm{M}}^{\mathrm{RM}} / \partial \omega^{\mathrm{RM}}{ }^{2}\right)$ $=-1<0, \quad\left(\partial^{2} \pi_{\mathrm{M}}^{\mathrm{RM}} / \partial r^{\mathrm{RM}^{2}}\right)=1 / 4(-3+m) m<0$, and $\left(\partial^{2} \pi_{\mathrm{M}}^{\mathrm{RM}} / \partial \omega^{\mathrm{RM}}{ }^{2}\right)\left(\partial^{2} \pi_{\mathrm{M}}^{\mathrm{RM}} / \partial r^{\mathrm{RM}}{ }^{2}\right)-\left(\partial^{2} \pi_{\mathrm{M}}^{\mathrm{RM}} / \partial \omega^{\mathrm{RM}}\right.$ $\left.\partial r^{\mathrm{RM}}\right)\left(\partial^{2} \pi_{\mathrm{M}}^{\mathrm{RM}} / \partial r^{\mathrm{RM}} \partial \omega^{\mathrm{RM}}\right)=\left(-8 m^{2}+8 m-1 / 16\right)$ $>0$ for any $m \in((2-\sqrt{2} / 4),(2+\sqrt{2} / 4))$. Therefore, the profits of the retailer and manufacturer satisfy the second-order condition for the maximum.

(3) For $\mathrm{Z}^{s} \mathrm{~T}=\mathrm{RC}$, the retailer and manufacturer maximize their profits with the negative Hessian matrices due to $\left(\partial^{2} \pi_{\mathrm{R}}^{\mathrm{RC}} / \partial p^{\mathrm{RC}}{ }^{2}\right)=-2<0, \quad\left(\partial^{2} \pi_{\mathrm{M}}^{\mathrm{RC}} / \partial \omega^{\mathrm{RC}}\right)$ $=-1<0, \quad\left(\partial^{2} \pi_{\mathrm{M}}^{\mathrm{RC}} / \partial r^{\mathrm{RC}}{ }^{2}\right)<0, \quad$ and $\quad\left(\partial^{2} \pi_{\mathrm{M}}^{\mathrm{RC}} / \partial \omega^{\mathrm{RC}}{ }^{2}\right)$ $\left(\partial^{2} \pi_{\mathrm{M}}^{\mathrm{RC}} / \partial r^{\mathrm{RC}}\right)-\left(\partial^{2} \pi_{\mathrm{M}}^{\mathrm{RC}} / \partial \omega^{\mathrm{RC}} \partial r^{\mathrm{RC}}\right)\left(\partial^{2} \pi_{\mathrm{M}}^{\mathrm{RC}} / \partial r^{\mathrm{RC}}\right.$ $\left.\partial \omega^{\mathrm{RC}}\right) \geq 0$ for any $\theta \in(0,1]$. Thus, the profits of the retailer and manufacturer satisfy the second-order condition for the maximum.

In the duopoly supply chain system, we have the following:

(1) For $\mathrm{Z}^{\mathrm{d}} \mathrm{T}=\mathrm{NNN}$, the retailer and manufacturers maximize their profits with the negative Hessian matrices due to

$$
\begin{array}{r}
\frac{\partial^{2} \pi_{\mathrm{R}}^{\mathrm{NNN}}}{\partial p_{\mathrm{i}}^{\mathrm{NNN}}}=-\frac{2}{1-\gamma^{2}}<0, \\
\frac{\partial^{2} \pi_{\mathrm{R}}^{\mathrm{NNN}}}{\partial p_{\mathrm{X}}^{\mathrm{NNN}}} \frac{\partial^{2} \pi_{\mathrm{R}}^{\mathrm{NNN}}}{\partial p_{\mathrm{Y}}^{\mathrm{NNN}}}-\frac{\partial^{2} \pi_{\mathrm{R}}^{\mathrm{NNN}}}{\partial p_{\mathrm{X}}^{\mathrm{NNN}} \partial_{\mathrm{Y}}^{\mathrm{NNN}}} \frac{\partial^{2} \pi_{\mathrm{R}}^{\mathrm{NNN}}}{\partial p_{\mathrm{Y}}^{\mathrm{NNN}} \partial p_{\mathrm{X}}^{\mathrm{NNN}}}=\frac{4}{1-\gamma^{2}}>0, \\
\frac{\partial^{2} \pi_{\mathrm{i}}^{\mathrm{NNN}}}{\partial \omega_{\mathrm{i}}^{\mathrm{NNN}}}=-\frac{1}{1-\gamma^{2}}<0,
\end{array}
$$

for any $\gamma \in[0,1)$. Therefore, the profits of the retailer and manufacturers satisfy the second-order condition for the maximum.
(2) For $Z^{\mathrm{d}} \mathrm{T}=\mathrm{RRM}$, the retailer and manufacturers maximize their profits with the negative Hessian matrices due to 


$$
\begin{aligned}
& \frac{\partial^{2} \pi_{\mathrm{R}}^{\mathrm{RRM}}}{\partial p_{\mathrm{i}}^{\mathrm{RRM}}}=-\frac{2}{1-\gamma^{2}}<0 \\
& \frac{\partial^{2} \pi_{\mathrm{R}}^{\mathrm{RRM}}}{\partial p_{\mathrm{X}}^{\mathrm{RRM}}{ }^{2}} \frac{\partial^{2} \pi_{\mathrm{R}}^{\mathrm{RRM}}}{\partial p_{\mathrm{Y}}^{\mathrm{RRM}}{ }^{2}}-\frac{\partial^{2} \pi_{\mathrm{R}}^{\mathrm{RRM}}}{\partial p_{\mathrm{X}}^{\mathrm{RRM}} \partial_{\mathrm{Y}}^{\mathrm{RRM}}} \frac{\partial^{2} \pi_{\mathrm{R}}^{\mathrm{RRM}}}{\partial p_{\mathrm{Y}}^{\mathrm{RRM}} \partial p_{\mathrm{X}}^{\mathrm{RRM}}}=\frac{4}{1-\gamma^{2}}>0, \\
& \frac{\partial^{2} \pi_{\mathrm{i}}^{\mathrm{RRM}}}{\partial \omega_{\mathrm{i}}^{\mathrm{RRM}}{ }^{2}}=-\frac{1}{1-\gamma^{2}}<0, \\
& \frac{\partial^{2} \pi_{\mathrm{i}}^{\mathrm{RRM}}}{\partial r_{\mathrm{i}}^{\mathrm{RRM}}}=-\frac{3}{2\left(1-\gamma^{2}\right)}<0, \\
& \frac{\partial^{2} \pi_{i}^{\mathrm{RRM}}}{\partial \omega_{\mathrm{i}}^{\mathrm{RRM}}{ }^{2}} \frac{\partial^{2} \pi_{\mathrm{i}}^{\mathrm{RRM}}}{\partial r_{\mathrm{i}}^{\mathrm{RRM}}{ }^{2}}-\frac{\partial^{2} \pi_{\mathrm{i}}^{\mathrm{RRM}}}{\partial \omega_{\mathrm{i}}^{\mathrm{RRM}} \partial r_{\mathrm{i}}^{\mathrm{RRM}}} \frac{\partial^{2} \pi_{\mathrm{i}}^{\mathrm{RRM}}}{\partial r_{\mathrm{i}}^{\mathrm{RRM}} \partial \omega_{\mathrm{i}}^{\mathrm{RRM}}}=\frac{-8 m^{2}+8 m-1}{16\left(1-\gamma^{2}\right)}>0,
\end{aligned}
$$

for any $m \in((2-\sqrt{2} / 4),(2+\sqrt{2} / 4))$ and $\gamma \in[0,1)$. Therefore, the profits of the retailer and manufacturer satisfy the second-order condition for the maximum.
(3) For $Z^{\mathrm{d}} \mathrm{T}=\mathrm{RRC}$, the retailer and manufacturers maximize their profits with the negative Hessian matrices due to

$$
\begin{aligned}
& \frac{\partial^{2} \pi_{\mathrm{R}}^{\mathrm{RRC}}}{\partial p_{\mathrm{i}}^{\mathrm{RRC}}}=-\frac{2}{1-\gamma^{2}}<0, \\
& \frac{\partial^{2} \pi_{\mathrm{R}}^{\mathrm{RRC}}}{\partial p_{\mathrm{X}}^{\mathrm{RRC}}{ }^{2}} \frac{\partial^{2} \pi_{\mathrm{R}}^{\mathrm{RRC}}}{\partial p_{\mathrm{Y}}^{\mathrm{RRM}}{ }^{2}}-\frac{\partial^{2} \pi_{\mathrm{R}}^{\mathrm{RRC}}}{\partial p_{\mathrm{X}}^{\mathrm{RRC}} \partial_{\mathrm{Y}}^{\mathrm{RRC}}} \frac{\partial^{2} \pi_{\mathrm{R}}^{\mathrm{RRC}}}{\partial p_{\mathrm{Y}}^{\mathrm{RRC}} \partial p_{\mathrm{X}}^{\mathrm{RRC}}}=\frac{4}{1-\gamma^{2}}>0, \\
& \frac{\partial^{2} \pi_{\mathrm{i}}^{\mathrm{RRC}}}{\partial \omega_{\mathrm{i}}^{\mathrm{RRC}}}=-\frac{1}{1-\gamma^{2}}<0 \\
& \frac{\partial^{2} \pi_{\mathrm{i}}^{\mathrm{RRC}}}{\partial r_{\mathrm{i}}^{\mathrm{RRC}}}<0 \\
& \frac{\partial^{2} \pi_{i}^{R R C}}{\partial \omega_{i}^{R R C}{ }^{2}} \frac{\partial^{2} \pi_{i}^{R R C}}{\partial r_{i}^{R R C}}-\frac{\partial^{2} \pi_{i}^{R R C}}{\partial \omega_{i}^{R R C} \partial r_{i}^{R R C}} \frac{\partial^{2} \pi_{i}^{R R C}}{\partial r_{i}^{R R C} \partial \omega_{i}^{R R C}} \geq 0,
\end{aligned}
$$

for any $\theta \in(0,1]$ and $\gamma \in[0,1)$. Thus, the profits of the retailer and manufacturer satisfy the secondorder condition for the maximum.

\section{Proof of Lemma 1}

For Part (i), $\omega^{\mathrm{RM}}, r^{\mathrm{RM}}, p^{\mathrm{RM}}, \pi_{\mathrm{R}}^{\mathrm{RM}}$, and $\pi_{\mathrm{M}}^{\mathrm{RM}}$ initially decrease and then increase in $m$ because 


$$
\begin{aligned}
& \frac{\partial \omega^{\mathrm{RM}}}{\partial m}=\frac{a\left(-5+8 m+8 m^{2}\right)}{\left(1-8 m+8 m^{2}\right)^{2}}<0, \quad \text { for } m \in\left(\frac{2-\sqrt{2}}{4}, \frac{\sqrt{14}-2}{4}\right), \\
& \frac{\partial \omega^{\mathrm{RM}}}{\partial m}=\frac{a\left(-5+8 m+8 m^{2}\right)}{\left(1-8 m+8 m^{2}\right)^{2}}>0, \quad \text { for } m \in\left[\frac{\sqrt{14}-2}{4}, \frac{2+\sqrt{2}}{4}\right), \\
& \frac{\partial r^{\mathrm{RM}}}{\partial m}=\frac{2 a(-8+16 m)}{\left(1-8 m+8 m^{2}\right)^{2}}<0, \quad \text { for } m \in\left(\frac{2-\sqrt{2}}{4}, \frac{1}{2}\right) \text {, } \\
& \frac{\partial r^{\mathrm{RM}}}{\partial m}=\frac{2 a(-8+16 m)}{\left(1-8 m+8 m^{2}\right)^{2}}>0, \quad \text { for } m \in\left[\frac{1}{2}, \frac{2+\sqrt{2}}{4}\right) \\
& \frac{\partial p^{\mathrm{RM}}}{\partial m}=\frac{a\left(-7+12 m+8 m^{2}\right)}{\left(1-8 m+8 m^{2}\right)^{2}}<0, \quad \text { for } m \in\left[\frac{1}{2}, \frac{2+\sqrt{2}}{4}\right), \\
& \frac{\partial p^{\mathrm{RM}}}{\partial m}=\frac{a\left(-7+12 m+8 m^{2}\right)}{\left(1-8 m+8 m^{2}\right)^{2}}<0, \quad \text { for } m \in\left(\frac{2-\sqrt{2}}{4}, \frac{\sqrt{23}-3}{4}\right) \\
& \frac{\partial p^{\mathrm{RM}}}{\partial m}=\frac{a\left(-7+12 m+8 m^{2}\right)}{\left(1-8 m+8 m^{2}\right)^{2}}>0, \quad \text { for } m \in\left[\frac{\sqrt{23}-3}{4}, \frac{2+\sqrt{2}}{4}\right), \\
& \frac{\partial \pi_{\mathrm{R}}^{\mathrm{RM}}}{\partial m}=\frac{8 a^{2} m\left(1-3 m+2 m^{2}\right)}{\left(1-8 m+8 m^{2}\right)^{3}}<0, \quad \text { for } m \in\left(\frac{2-\sqrt{2}}{4}, \frac{1}{2}\right), \\
& \frac{\partial \pi_{\mathrm{R}}^{\mathrm{RM}}}{\partial m}=\frac{8 a^{2} m\left(1-3 m+2 m^{2}\right)}{\left(1-8 m+8 m^{2}\right)^{3}}>0, \quad \text { for } m \in\left[\frac{1}{2}, \frac{2+\sqrt{2}}{4}\right) \\
& \frac{\partial \pi_{\mathrm{M}}^{\mathrm{RM}}}{\partial m}=\frac{a^{2}(-1+2 m)}{\left(1-8 m+8 m^{2}\right)^{2}}<0, \quad \text { for } m \in\left(\frac{2-\sqrt{2}}{4}, \frac{1}{2}\right), \\
& \frac{\partial \pi_{\mathrm{M}}^{\mathrm{RM}}}{\partial m}=\frac{a^{2}(-1+2 m)}{\left(1-8 m+8 m^{2}\right)^{2}}>0, \quad \text { for } m \in\left[\frac{1}{2}, \frac{2+\sqrt{2}}{4}\right) .
\end{aligned}
$$

For Part (ii), we can derive the conclusion from these details.

\section{Proof of Lemma 2}

In the monopoly supply chain system, if the retailer does not exert rebate discrimination on customers with rebate sensitivity under the channel rebate, then we can obtain ${ }_{r}^{\mathrm{RC}}=0$. If the retailer exerts rebate discrimination on customers with rebate sensitivity under the channel rebate, then we can derive $\omega^{\mathrm{RC}}=r^{\mathrm{RC}}-2 a<0$.

\section{Proof of Proposition 1}

With the profits of the manufacturer and retailer indicated in the monopoly system, for $a>0$ and

$$
\begin{gathered}
m \in\left(\frac{2-\sqrt{2}}{4}, \frac{2+\sqrt{2}}{4}\right), \\
\pi_{\mathrm{M}}^{\mathrm{RM}}-\pi_{\mathrm{M}}^{\mathrm{NN}}\left(\pi_{\mathrm{M}}^{\mathrm{RC}}\right)=-\frac{a^{2}}{8\left(1-8 m+8 m^{2}\right)}>0, \\
\pi_{\mathrm{R}}^{\mathrm{RM}}-\pi_{\mathrm{R}}^{\mathrm{NN}}\left(\pi_{\mathrm{R}}^{\mathrm{RC}}\right)=\frac{a^{2}[16(1-m) m-1]}{16[1+8(-1+m) m]^{2}}>0 .
\end{gathered}
$$

Proof of Lemma 3

For Parts (i) and (ii), $\omega_{i}^{\mathrm{RRM}}$ initially decreases and then increases in $m$ if $\gamma<\gamma_{1}$, where $\gamma_{1}=0.477592$. Given that $0<\gamma<0.477592$, 


$$
\begin{aligned}
& \frac{\partial \omega_{\mathrm{i}}^{\mathrm{RRM}}}{\partial m}=\frac{a(1-\gamma)\left[-5+2 m^{2}(-2+\gamma)^{2}+7 \gamma-2 \gamma^{2}+4 m\left(2-3 \gamma+\gamma^{2}\right)\right]}{\left[-1+2 m(-2+\gamma)^{2}-2 m^{2}(-2+\gamma)^{2}+\gamma\right]^{2}}<0, \quad \text { with } m \in\left(\frac{2-\sqrt{2}}{4}, \frac{\sqrt{14}-2}{4}\right), \\
& \frac{\partial \omega_{\mathrm{i}}^{\mathrm{RRM}}}{\partial m}=\frac{a(1-\gamma)\left[-5+2 m^{2}(-2+\gamma)^{2}+7 \gamma-2 \gamma^{2}+4 m\left(2-3 \gamma+\gamma^{2}\right)\right]}{\left[-1+2 m(-2+\gamma)^{2}-2 m^{2}(-2+\gamma)^{2}+\gamma\right]^{2}}>0, \quad \text { with } m \in\left[\frac{\sqrt{14}-2}{4}, \frac{2+\sqrt{2}}{4}\right) .
\end{aligned}
$$

However, for $0.477592 \leq \gamma<1$,

$$
\frac{\partial \omega_{\mathrm{i}}^{\mathrm{RRM}}}{\partial m}=\frac{a(1-\gamma)\left[-5+2 m^{2}(-2+\gamma)^{2}+7 \gamma-2 \gamma^{2}+4 m\left(2-3 \gamma+\gamma^{2}\right)\right]}{\left[-1+2 m(-2+\gamma)^{2}-2 m^{2}(-2+\gamma)^{2}+\gamma\right]^{2}}>0, \quad m \in\left(\frac{2-\sqrt{2}}{4}, \frac{2+\sqrt{2}}{4}\right) .
$$

For Parts (iii) and (iv), the conclusion with respect to $p_{\mathrm{i}}^{\mathrm{RRM}}$ is true because for $0<\gamma<0.792893$,

$$
\begin{aligned}
& \frac{\partial p_{\mathrm{i}}^{\mathrm{RRM}}}{\partial m}=\frac{a(1-\gamma)\left[-7+2 m^{2}(-2+\gamma)^{2}+8 \gamma-2 \gamma^{2}+2 m\left(6-7 \gamma+2 \gamma^{2}\right)\right]}{\left[-1+2 m(-2+\gamma)^{2}-2 m^{2}(-2+\gamma)^{2}+\gamma\right]^{2}}<0, \quad \text { with } m \in\left(\frac{2-\sqrt{2}}{4}, \frac{\sqrt{23}-3}{4}\right), \\
& \frac{\partial p_{\mathrm{i}}^{\mathrm{RRM}}}{\partial m}=\frac{a(1-\gamma)\left[-7+2 m^{2}(-2+\gamma)^{2}+8 \gamma-2 \gamma^{2}+2 m\left(6-7 \gamma+2 \gamma^{2}\right)\right]}{\left[-1+2 m(-2+\gamma)^{2}-2 m^{2}(-2+\gamma)^{2}+\gamma\right]^{2}}>0, \quad \text { with } m \in\left[\frac{\sqrt{23}-3}{4}, \frac{2+\sqrt{2}}{4}\right) .
\end{aligned}
$$

However, for $0.792893 \leq \gamma<1$,

$$
\frac{\partial p_{\mathrm{i}}^{\mathrm{RRM}}}{\partial m}=\frac{a(1-\gamma)\left[-7+2 m^{2}(-2+\gamma)^{2}+8 \gamma-2 \gamma^{2}+2 m\left(6-7 \gamma+2 \gamma^{2}\right)\right]}{\left[-1+2 m(-2+\gamma)^{2}-2 m^{2}(-2+\gamma)^{2}+\gamma\right]^{2}}>0, \quad \text { with } m \in\left(\frac{2-\sqrt{2}}{4}, \frac{2+\sqrt{2}}{4}\right)
$$

where $\gamma_{2}=0.792893$.

\section{Proof of Lemma 4}

$r_{\mathrm{i}}^{\mathrm{RRM}}, \pi_{\mathrm{i}}^{\mathrm{RRM}}$, and $\pi_{\mathrm{R}}^{\mathrm{RRM}}$ initially decrease and then increase in $m$ with any $\gamma$ because

$$
\begin{aligned}
& \frac{\partial r_{\mathrm{i}}^{\mathrm{RRM}}}{\partial m}=\frac{4 a(-1+2 m)(-2+\gamma)^{2}(1-\gamma)}{\left[-1+2 m(-2+\gamma)^{2}-2 m^{2}(-2+\gamma)^{2}+\gamma\right]^{2}}<0, \\
& \frac{\partial \pi_{\mathrm{R}}^{\mathrm{RRM}}}{\partial m}=\frac{4 a^{2} m\left(1-3 m+2 m^{2}\right)(-2+\gamma)^{2}(1-\gamma)}{\left[1-2 m(-2+\gamma)^{2}+2 m^{2}(-2+\gamma)^{2}-\gamma\right]^{3}(1+\gamma)}<0, \\
& \frac{\partial \pi_{\mathrm{M}}^{\mathrm{RM}}}{\partial m}=\frac{a^{2}(-1+2 m)(-1+\gamma)^{2}}{(1+\gamma)\left[-1+2 m(-2+\gamma)^{2}-2 m^{2}(-2+\gamma)^{2}+\gamma\right]^{2}}<0, \quad \text { for } m \in\left(\frac{2-\sqrt{2}}{4}, \frac{1}{2}\right) .
\end{aligned}
$$


In addition,

$$
\begin{aligned}
& \frac{\partial r_{\mathrm{i}}^{\mathrm{RRM}}}{\partial m}=\frac{4 a(-1+2 m)(-2+\gamma)^{2}(1-\gamma)}{\left[-1+2 m(-2+\gamma)^{2}-2 m^{2}(-2+\gamma)^{2}+\gamma\right]^{2}}>0, \\
& \frac{\partial \pi_{\mathrm{R}}^{\mathrm{RRM}}}{\partial m}=\frac{4 a^{2} m\left(1-3 m+2 m^{2}\right)(-2+\gamma)^{2}(1-\gamma)}{\left[1-2 m(-2+\gamma)^{2}+2 m^{2}(-2+\gamma)^{2}-\gamma\right]^{3}(1+\gamma)}>0, \\
& \frac{\partial \pi_{\mathrm{M}}^{\mathrm{RM}}}{\partial m}=\frac{a^{2}(-1+2 m)(-1+\gamma)^{2}}{(1+\gamma)\left[-1+2 m(-2+\gamma)^{2}-2 m^{2}(-2+\gamma)^{2}+\gamma\right]^{2}}>0, \quad \text { for } m \in\left[\frac{1}{2}, \frac{2+\sqrt{2}}{4}\right) .
\end{aligned}
$$

\section{Proof of Proposition 2}

With the profits of the manufacturers and retailer provided in the duopoly system, for $0 \leq \gamma<1$ and $m \in(2-\sqrt{2} / 4,(2+\sqrt{2} / 4))$,

$$
\begin{aligned}
& \pi_{\mathrm{M}}^{\mathrm{RRM}}-\pi_{\mathrm{M}}^{\mathrm{NNN}}\left(\pi_{\mathrm{M}}^{\mathrm{RRC}}\right)=-\frac{a^{2}(-1+\gamma)^{2}}{2\left[1-2 m(-2+\gamma)^{2}+2 m^{2}(-2+\gamma)^{2}-\gamma\right](-2+\gamma)^{2}(1+\gamma)}>0, \\
& \pi_{\mathrm{R}}^{\mathrm{RRM}}-\pi_{\mathrm{R}}^{\mathrm{NNN}}\left(\pi_{\mathrm{R}}^{\mathrm{RRC}}\right)=\frac{a^{2}\left(1+4(-1+m) m(-2+\gamma)^{2}-\gamma\right)(-1+\gamma)}{2(-2+\gamma)^{2}(1+\gamma)\left[-1-2(-1+m) m(-2+\gamma)^{2}+\gamma\right]^{2}}>0 .
\end{aligned}
$$

\section{Proof of Proposition 3}

For Part (ii), if the manufacturer offers $\mathrm{r}^{\text {sTSC }}=\left(2 a\left(-2+m^{2}\right) / 1-8 m+8 m^{2}\right)$, then we can derive $\pi_{\mathrm{M}}^{\mathrm{sTSC}}=\left(a^{2}(-1+m) m / 1-8 m+8 m^{2}\right)$, which is equal to the no-coordination policy. For Part (iii), if the manufacturer offers $r_{\mathrm{M}}^{\mathrm{sTSC}}=\left(a\left(-3+m^{2}\right) / 1-8 m+8 m^{2}\right)$, then we can obtain

$$
\pi_{\mathrm{R}}^{\mathrm{sTSC}}=-\frac{a^{2}(-1+m)^{2} m\left[-4 m+a\left(1+4 m+m^{2}\right)\right]}{\left(1-8 m+8 m^{2}\right)^{2}}<\pi_{\mathrm{R}}^{\mathrm{RM}}=\frac{4 a^{2}(-1+m)^{2} m^{2}}{[1+8(-1+m) m]^{2}}, \quad m \in\left(\frac{2-\sqrt{2}}{4}, \frac{2+\sqrt{2}}{4}\right) .
$$

\section{Proof of Proposition 4}

For Part (ii), if the manufacturer offers $r^{\mathrm{dTSC}}=(a[-8+$ $\left.9 \gamma+m \gamma-2 \gamma^{2}+2 m^{2}\left(2-3 \gamma+\gamma^{2}\right)\right] / 2\left[1-2 m(-2+\gamma)^{2}+2 m^{2}\right.$ $\left.\left.(-2+\gamma)^{2}-\gamma\right]\right)$, then we can derive

$$
\begin{gathered}
\pi_{\mathrm{M}}^{\mathrm{dTSC}}-\pi_{\mathrm{M}}^{\mathrm{RRM}}=\frac{a^{2}(-1+m)^{2} m \gamma\left[-12+4 m^{2}(-2+\gamma)^{2}(-1+\gamma)+23 \gamma-16 \gamma^{2}+4 \gamma^{3}+m\left(-28+54 \gamma-36 \gamma^{2}+8 \gamma^{3}\right)\right]}{8(1+\gamma)\left[-1+2 m(-2+\gamma)^{2}-2 m^{2}(-2+\gamma)^{2}+\gamma\right]^{2}}<0, \\
\text { for } m \in\left(\frac{2-\sqrt{2}}{4}, \frac{2+\sqrt{2}}{4}\right),
\end{gathered}
$$


and $0 \leq \gamma<1$. For Part (iii), if the manufacturer offers $r_{\mathrm{M}}^{\mathrm{dTSC}}=$ $\left(a\left(-3+m^{2}\right)(1-\gamma) / 1-2 m(-2+\gamma)^{2}+2 m^{2}(-2+\gamma)^{2}-\gamma\right)$, then we can obtain

$$
\begin{aligned}
& \pi_{\mathrm{R}}^{\mathrm{dTSC}}-\pi_{\mathrm{R}}^{\mathrm{RRM}}=\frac{a^{2}(-1+m)^{2}\left[8+4 m^{3}(-2+\gamma)(-1+\gamma)^{3}-22 \gamma+27 \gamma^{2}-16 \gamma^{3}+4 \gamma^{4}+2 m^{2}\left(4-43 \gamma+61 \gamma^{2}-32 \gamma^{3}+6 \gamma^{4}\right)+m\left(40-104 \gamma+117 \gamma^{2}-60 \gamma^{3}+12 \gamma^{4}\right)\right]}{4(1+\gamma)\left[-1+2 m(-2+\gamma)^{2}-2 m^{2}(-2+\gamma)^{2}+\gamma\right]^{2}}<0, \\
& \pi_{\mathrm{M}}^{\mathrm{dTC}}-\pi_{\mathrm{M}}^{\mathrm{RRM}}=\frac{a^{2}(-1+m)^{2} m(-1+\gamma)\left[2(-1+\gamma)^{2}(-3+2 \gamma)+2 m^{2}(-2+\gamma)^{2}(-1+2 \gamma)+m\left(-14+39 \gamma-32 \gamma^{2}+8 \gamma^{3}\right)\right]}{4(1+\gamma)\left[-1+2 m(-2+\gamma)^{2}-2 m^{2}(-2+\gamma)^{2}+\gamma\right]^{2}}<0, \quad \text { for } m \in\left(\frac{2-\sqrt{2}}{4}, \frac{2+\sqrt{2}}{4}\right),
\end{aligned}
$$

and $0 \leq \gamma<1$.

$$
\pi_{\mathrm{M}}^{\mathrm{BR}}-\pi_{\mathrm{M}}^{\mathrm{NN}}=\left(a^{2}(m-\theta) / 8\{\theta+m[1+2(-2+\theta) \theta]\}\right)>0,
$$

Proof of Proposition 5

Given $\pi_{M}^{N N}, \pi_{M}^{B R}, \pi_{R}^{N N}$, and $\pi_{R}^{B R}$ in the monopoly setting, we can derive that

for $0<\theta \leq 0.5, \theta<m<1$, and $0.5<\theta<1 ; \theta<m<-(\theta / 1-$ $\left.4 \theta+2 \theta^{2}\right)$, and

$$
\pi_{\mathrm{R}}^{\mathrm{BR}}-\pi_{\mathrm{R}}^{\mathrm{NN}}=\frac{a^{2}\left[2 m \theta\left(1+8 \theta-8 \theta^{2}\right)+\theta^{2}\left(-5+4 \theta^{2}\right)+m^{2}\left(3-16 \theta+12 \theta^{2}\right)\right]}{16\left(m+\theta-4 m \theta+2 m \theta^{2}\right)^{2}}>0,
$$

for $0<\theta \leq 0.5 \theta<m<1$, and $0.5<\theta<1 ; \quad \theta<m<(-5 \theta+$ $\left.4 \theta^{3} / 3-16 \theta+12 \theta^{2}\right)$. Given $\pi_{\mathrm{M}}^{\mathrm{NNN}}, \pi_{\mathrm{M}}^{\mathrm{BRR}}, \pi_{\mathrm{R}}^{\mathrm{NNN}}$, and $\pi_{\mathrm{R}}^{\mathrm{BRR}}$ in the duopoly setting, we can derive that

$$
\pi_{\mathrm{M}}^{\mathrm{BRR}}-\pi_{\mathrm{M}}^{\mathrm{NNN}}=\frac{a^{2}(1-\gamma)(m-\theta)}{2(-2+\gamma)^{2}(1+\gamma)\left(m+\theta-4 m \theta+2 m \theta^{2}\right)}>0
$$

for $\quad 0<\theta \leq 0.5, \quad \theta<m<1, \quad 0 \leq \gamma<1$, and $0.5<\theta<1$, $\theta<m<-\left(\theta / 1-4 \theta+2 \theta^{2}\right), 0 \leq \gamma<1$, and

(B.18)

$$
\pi_{\mathrm{R}}^{\mathrm{BRR}}-\pi_{\mathrm{R}}^{\mathrm{NNN}}=\frac{-a^{2}(m-\theta)\left\{\theta\left[-5-4 \gamma(-1+\theta)+4 \theta^{2}\right]+m\left[-3-4(-4+\gamma) \theta+4(-3+\gamma) \theta^{2}\right]\right\}}{2(-2+\gamma)^{2}(1+\gamma)\left(m+\theta-4 m \theta+2 m \theta^{2}\right)^{2}}>0,
$$

for $\quad 0<\theta \leq 0.5, \theta<m<1, \quad 0 \leq \gamma<1, \quad$ and $\quad 0.5<\theta<1$, $\theta<m<-\left(\theta / 1-4 \theta+2 \theta^{2}\right), 0 \leq \gamma<1$ or $-\left(\theta / 1-4 \theta+2 \theta^{2}\right)<$ $m \leq\left(-\theta-4 \theta^{2}+4 \theta^{3} / 3-12 \theta+8 \theta^{2}\right), 0 \leq \gamma<1$, or $\left(-\theta-4 \theta^{2}+\right.$ $\left.4 \theta^{3} / 3-12 \theta+8 \theta^{2}\right)<m<\left(-5 \theta+4 \theta^{3} / 3-16 \theta+12 \theta^{2}\right), 0 \leq \gamma$ $<\left(3 m+5 \theta-16 m \theta+12 m \theta^{2}-4 \theta^{3} / 4 \theta-4 m \theta-4 \theta^{2}+4 m \theta^{2}\right)$.

Moreover, $m_{\theta>0.5}=-\left(\theta / 1-4 \theta+2 \theta^{2}\right)$ because $-(\theta / 1-4 \theta+$ $\left.2 \theta^{2}\right)<\left(-\theta-4 \theta^{2}+4 \theta^{3} / 3-12 \theta+8 \theta^{2}\right)<\left(-5 \theta+4 \theta^{3} / 3-16 \theta+\right.$ $\left.12 \theta^{2}\right)$.

\section{Data Availability}

No data were used to support this study.

\section{Conflicts of Interest}

The authors declare that there are no conflicts of interest regarding the publication of this paper.

\section{Acknowledgments}

The authors would like to disclose this research was supported by National Natural and Science Foundation of China (Grant number 71971134) and Cruise Program from the Ministry of Industrial Information and Technology of China (Grant number MC-201917-C09).

\section{References}

[1] P. R. Newswire, "One in every two retailers using rebates to drive customer responsiveness," 2011, http://www.prnewswire. $\mathrm{com} /$ news-releases/one-in-every-two-retailers-usingrebates-to -drive-customer -responsiveness-121651153.html.

[2] R. Parago, "2014 UK shopper behavior study," 2014, http:// www.slideshare.net/Parago/uk-shopperweb.

[3] M. Khouja, "A joint optimal pricing, rebate value, and lot sizing model," European Journal of Operational Research, vol. 174, no. 2, pp. 706-723, 2006. 
[4] License, "Shopping trips," License, vol. 8, no. 5, pp. 44-45, 2005.

[5] R. Lieber, "Finding extra discounts online," Wall Street Journal-Eastern Edition, vol. 246, no. 114, 2015.

[6] S. Mitra, "Analysis of a two-echelon inventory system with returnsts," Omega, vol. 37, no. 1, pp. 106-115, 2009.

[7] J. Pocock, "Complete systems," Apply, vol. 5, no. 7, pp. 4-7, 2005.

[8] E. Gerstner and J. D. Hess, "Pull promotions and channel coordination," Marketing Science, vol. 14, no. 1, pp. 43-60, 1995.

[9] D. Xing and T. Liu, "Sales effort free riding and coordination with price match and channel rebate," European Journal of Operational Research, vol. 219, no. 2, pp. 264-271, 2012.

[10] F. Preston, Consolidated Industry Seeks Out Top VARs, p. 41, Computer Reseller News, Westborough, MA, USA, 1999.

[11] E. F. Moltzen, Lotus Targets VARs to Beef up Support, p. 721, Computer Reseller News, 1997.

[12] L. Pender, Symantec Woos VAR Channel, pp. 159-160, Computer Reseller News, 1998.

[13] A. Y. Ha, W. Shang, and Y. Wang, "Manufacturer rebate competition in a supply chain with a common retailer," Production and Operations Management, vol. 26, no. 11, pp. 1-15, 2017.

[14] T. A. Taylor, "Supply chain coordination under channel rebates with sales effort effects," Management Science, vol. 48, no. 8, pp. 992-1007, 2002.

[15] A. Muzaffar, M. N. Malik, and A. Rashid, "Rebate mechanism for the manufacturer in two-level supply chains," Asia Pacific Management Review, vol. 23, no. 4, pp. 301-309, 2018.

[16] Y. Chen, S. Moorthy, and Z. J. Zhang, "Research note-price discrimination after the purchase: rebates as state-dependent discounts," Management Science, vol. 51, no. 7, pp. 1131-1140, 2005.

[17] S. M. Gilpatric, "Slippage in rebate programs and presentbiased preferences," Marketing Science, vol. 28, no. 2, pp. 229-238, 2009.

[18] M. Khouja and F. E. Vergara, "Single-period inventory model with a delayed incentive option for selling excess inventory," International Transactions in Operational Research, vol. 15, no. 3, pp. 359-379, 2008

[19] M. Kinsman, "The hard sell," PROMO Source Book, vol. 16, p. 19, 2004.

[20] V. Kumar, V. Madan, and S. S. Srinivasan, "Price discounts or coupon promotions: does it matter?" Journal of Business Research, vol. 57, no. 9, pp. 933-941, 2004.

[21] J. Wechsler, "Drug spending slows," Pharmaceutical Executive, vol. 27, no. 2, p. 28, 2007

[22] A. Wolf, "FTC issues rebate warning to retailers," TWICE: This Week in Consumer Electronics, vol. 20, no. 7, p. 6, 2005.

[23] S. Yang, C. L. Munson, and B. Chen, "Using MSRP to enhance the ability of rebates to control distribution channels," $E u$ ropean Journal of Operational Research, vol. 205, no. 1, pp. 127-135, 2010.

[24] M. Khouja, S. S. Robbins, and H. K. Rajagopalan, "Optimal pricing and delayed incentives in heterogeneous consumer market," Journal of Revenue and Pricing Management, vol. 7, no. 1, pp. 85-105, 2006.

[25] F. J. Arcelus, S. Kumar, and G. Srinivasan, "Retailer's response to alternate manufacturer's incentives under a single-period, price-dependent, stochastic-demand framework," Decision Sciences, vol. 36, no. 4, pp. 599-626, 2005.

[26] G. Aydin and E. L. Porteus, "Manufacturer-to-retailer versus manufacturer-to-consumer rebates in a supply chain," in
Retail Supply Chain Management," International Series in Operations Research \& Management Science, N. Agrawal and S. A. Smith, Eds., vol. vol. 122, pp. 237-270, Springer, Boston, MA, USA, 2009.

[27] O. C. Demirag, O. Baysar, P. Keskinocak, and J. L. Swann, "The effects of customer rebates and retailer incentives on a manufacturer's profits and sales," Naval Research Logistics (NRL), vol. 57, no. 1, pp. 88-108, 2010.

[28] F. J. Arcelus, R. Gor, and G. Srinivasan, "Price, rebate and order quantity decisions in a newsvendor framework with rebate-dependent recapture of lost sales," International Journal of Production Economics, vol. 140, no. 1, pp. 473-482, 2012.

[29] E. Gerstner and J. D. Hess, "A theory of channel price promotions," American Economic Review, vol. 81, no. 4, pp. 872-886, 1991.

[30] Q. Lu and S. Moorthy, "Coupons versus rebates," Marketing Science, vol. 26, no. 1, pp. 67-82, 2007.

[31] S. Cho, K. F. McCardle, and C. S. Tang, "Optimal Pricing and rebate strategies in a two-level supply chain," Production and Operations Management, vol. 18, no. 4, pp. 424-446, 2009.

[32] O. Baysar, O. Demirag, P. Keskinocak, and J. Swann, "The effects of customer rebates and retailer incentives on a manufacturer's profits and sales," Naval Research Logistics, vol. 57, no. 1, pp. 88-108, 2009.

[33] M. Khouja and J. Zhou, "The effect of delayed incentives on supply chain profits and consumer surplus," Production and Operations Management, vol. 19, no. 2, pp. 172-197, 2010.

[34] B. Liu, G. G. Cai, and A. A. Tsay, "Advertising in asymmetric competing supply chains," Production and Operations Management, vol. 23, no. 11, pp. 1845-1858, 2014.

[35] X. Pu, L. Gong, and X. Han, "Consumer free riding: coordinating sales effort in a dual-channel supply chain," Electronic Commerce Research and Applications, vol. 22, pp. 1-12, 2017.

[36] J. Chen, H. Zhang, and Y. Sun, "Implementing coordination contracts in a manufacturer Stackelberg dual-channel supply chain,” Omega, vol. 40, no. 5, pp. 571-583, 2012.

[37] G. Xu, B. Dan, X. Zhang, and C. Liu, "Coordinating a dualchannel supply chain with risk-averse under a two-way revenue sharing contract," International Journal of Production Economics, vol. 147, pp. 171-179, 2014.

[38] J. Heydari and M. Ghasemi, "A revenue sharing contract for reverse supply chain coordination under stochastic quality of returned products and uncertain remanufacturing capacity," Journal of Cleaner Production, vol. 197, pp. 607-615, 2018.

[39] T. Li, R. Zhang, S. Zhao, and B. Liu, "Low carbon strategy analysis under revenue-sharing and cost-sharing contracts," Journal of Cleaner Production, vol. 212, no. 1, pp. 1462-1477, 2019.

[40] H. Krishnan, R. Kapuscinski, and D. A. Butz, "Coordinating contracts for decentralized supply chains with retailer promotional effort," Management Science, vol. 50, no. 1, pp. 48-63, 2014.

[41] B. Liu, R. Zhang, and M. Xiao, "Joint decision on production and pricing for online dual channel supply chain system," Applied Mathematical Modelling, vol. 34, no. 12, pp. 42084218, 2010.

[42] B. Li, P.-W. Hou, P. Chen, and Q.-H. Li, "Pricing strategy and coordination in a dual channel supply chain with a risk-averse retailer," International Journal of Production Economics, vol. 178, pp. 154-168, 2016.

[43] S. Zhang and J. Zhang, "Contract preference with stochastic cost learning in a two-period supply chain under asymmetric 
information," International Journal of Production Economics, vol. 196, pp. 226-247, 2018.

[44] N. M. Modak, S. Panda, and S. S. Sana, "Three-echelon supply chain coordination considering duopolistic retailers with perfect quality products," International Journal of Production Economics, vol. 182, pp. 564-578, 2016.

[45] T. A. Taylor and W. Xiao, "Incentives for retailer forecasting: rebates vs. Returns," Management Science, vol. 55, no. 10, pp. 1654-1669, 2009.

[46] C.-H. Chiu, T.-M. Choi, G. Hao, and X. Li, "Innovative menu of contracts for coordinating a supply chain with multiple mean-variance retailers," European Journal of Operational Research, vol. 246, no. 3, pp. 815-826, 2015.

[47] Z. Wang, J. J. Mi, and B. Liu, "Rebate decisions and leadership strategy in competing supply chain with heterogeneous consumers," Mathematical Problems in Engineering, vol. 2018, Article ID 2598415, 20 pages, 2018.

[48] G. Cai, Y. Dai, and W. Zhang, "Modeling multichannel supply chain management with marketing mixes: a survey," Social Science Electronic Publishing, vol. 15, 2015.

[49] R. Zhang, B. Liu, and W. Wang, "Pricing decisions in a dual channels system with different power structures," Economic Modelling, vol. 29, no. 2, pp. 523-533, 2012.

[50] H. Chung and E. Lee, "Asymmetric relationships with symmetric suppliers: strategic choice of supply chain price leadership in a competitive market," European Journal of Operational Research, vol. 259, no. 2, pp. 564-575, 2017.

[51] X. Chen, C.-L. Li, B.-D. Rhee, and D. Simchi-Levi, "The impact of manufacturer rebates on supply chain profits," Naval Research Logistics, vol. 54, no. 6, pp. 667-680, 2007.

[52] J. Tasoff and R. Letzler, "Everyone believes in redemption: nudges and overoptimism in costly task completion," Journal of Economic Behavior \& Organization, vol. 107, pp. 107-122, 2014. 